\title{
Razões e meios para o envolvimento com a proposta de Heinrich Schenker
}

Reasons and means for involvement with Heinrich Schenker's proposal

Adriana Lopes Moreira ${ }^{1}$ Universidade de São Paulo adrianalopes@usp.br

Maria Lúcia Pascoal Universidade Estadual de Campinas mlpascoal@gmail.com 


\section{Resumo}

A expansão da percepção de obras musicais que emerge do contato de músicos com a proposta schenkeriana é valorizada neste artigo. Para tanto, as autoras compartilham com o leitor suas experiências docentes junto ao ensino dessa prática analítica, em interlocução com processos harmônicos, contrapontísticos e texturais.

Palavras-chave: Heinrich Schenker. Motivo musical. Contraponto musical. Harmonia musical. Gráfico musical em multiníveis.

\section{Abstract}

The expansion of the perception of musical works that emerges from the contact of musicians with the Schenkerian proposal is valued in this article. Therefore, the authors share with the reader their experience with the teaching of this anatictical practice, in dialogue with harmonic, contrapuntal and textural processes..

Keywords: Heinrich Schenker. Musical motif. Musical counterpoint. Musical harmony. Musical multilevel graphic.

1 Adriana Lopes da Cunha Moreira é Doutora em Música (UNICAMP, 2008), pianista, professora livre-docente no Departamento de Música (CMU) da Escola de Comunicações e Artes (ECA) da Universidade de São Paulo (USP, 2004-) e professora efetiva no Programa de Pós-Graduação em Música da ECA-USP (2010-). É coordenadora da Graduação do CMU (2017-21), coordenadora do Grupo de Pesquisa TRAMA: Teoria e Análise Musical, voltado à aplicação de conceitos teóricos emergentes para a prática analítica de obras musicais (USP, CNPq, 2015-), e co-coordenadora dos Encontros Internacionais de Teoria e Analise Musical, EITAM (2009, 2011, 2013, 2017, 2019). Foi editora-chefe de publicações da ANPPOM (2011-15), que englobam a Revista OPUS (Qualis-CAPES A1), série Pesquisa em Música no Brasil e coordenação científica dos congressos anuais.

2 Maria Lúcia Pascoal é Doutora em Música (UNICAMP), professora e pesquisadora na área de Teoria e Análise no Departamento de Música do Instituto de Artes da UNICAMP, nos cursos de Graduação e Pós-Graduação. Seu trabalho de Análise Musical desenvolve principalmente o estudo da música brasileira dos séculos XX e XXI. Colabora nas principais publicações especializadas em música no Brasil e participa de encontros e congressos nacionais e internacionais, entre os quais o Orpheus Music Theory Seminar em Ghent (Bélgica) e Seminário Internacional Jorge Peixinho "Mémoires" (Portugal). É autora de Estrutura Tonal: Harmonia (Cia. Editora Paulista). Foi editora da revista OPUS da ANPPOM e é membro fundador da Associação Brasileira de Teoria e Análise Musical TeMA, da qual é vice-presidente no biênio 2021-2023. 
Quais têm sido os caminhos percorridos por uma proposta de análise musical inovadora, com base em uma teoria que sintetiza a estrutura harmônico-melódica contrapontisticamente e a apresenta em gráficos que refletem a audição como protagonista dessa análise?

Em 1952, Milton Babbitt (In: PELES et al., 2012, p. 19) definiu a proposta schenkeriana como "um corpo de procedimentos analíticos que refletem a percepção de uma obra musical como uma totalidade dinâmica"3. Quase sessenta anos depois, ao avaliar o contexto atual dos países de língua inglesa, o teórico cognitivo estadunidense David Temperley (2011, p. 146) a descreve como "a abordagem dominante para a análise da música tonal nos países de língua inglesa, [...] uma força poderosa e pervasiva [...], o próximo passo padrão na análise tonal após os fundamentos do núcleo de graduação; [...] ou de pós-graduação". ${ }^{4}$

O trabalho teórico de Heinrich Schenker (1868-1935), desenvolvido em Viena (Áustria), desde as primeiras décadas do século passado, chega aos EUA na época da Segunda Guerra Mundial, principalmente através de seus ex-alunos Oswald Jonas (1897-1978), Ernst Oster (1908-1977) e Felix Salzer (1904-1986), que para lá emigraram. O teórico e estudioso de Schenker, William Rothstein, apresenta a polêmica travada então, no ensaio ao qual denominou "A Americanização de Heinrich Schenker". Os três ex-alunos iniciaram publicações a partir dos textos de Schenker. Rothstein $(1986$, p. 9) observa como "a expansão do império shenkeriano se acelerou desde a publicação de Free Composition" ${ }^{5}$ e, ao lado de novos adeptos, formaram-se então alguns fortes opositores ${ }^{6}$.

É nesse contexto que surge, em 1952, a publicação de Felix Salzer, Structural Hearing, com o subtítulo Coerência tonal na música. O livro apresenta, em gráficos e exemplos da literatura musical, tópicos como Gramática e significado do acorde, Música como direção do movimento, Harmonia e contraponto, Prolongamento do acorde, Tonalidade e implicações de estrutura e prolongamento. Rothstein (1986, p. 11) testemunha a clareza e a forma didática do livro de Salzer para estudantes ainda não familiarizados com as análises de Shenker ${ }^{7}$. Como Diretor do Mannes College (New York), Leopold Mannes (In: Salzer, 1962 [1952], viii), afirma no Prefácio do livro, que "o trabalho pioneiro de Schenker foi modificado, expandido

\footnotetext{
3 "But what Schenker has contributed is a body of analytical procedures which reflect the perception of a musical work as a dynamic totality, not as a succession of moments or a juxtaposition of 'formal' areas related or contrasted merely by the fact of thematic or harmonic similarity or dissimilarity" (BABBITT, 1952. In: PELES et al., 2012, p. 19).

4 "More than seventy years after Schenker's death, Schenkerian theory remains the dominant approach to the analysis of tonal music in the English-speaking world. Schenkerian analyses seem as plentiful as ever in music theory journals and conference presentations. Recent bibliographical works, translations of Schenker's writings, and extensions of the theory to non-canonical repertories testify to the theory's continuing vitality. In music theory pedagogy, Schenker remains a powerful and pervasive force. [...] Schenkerian analysis remains the standard next step in tonal analysis after the rudiments of the undergraduate core; [...] or upper-level undergraduate courses" (TEMPERLEY, 2011, p. 146).

5 Free composition foi publicado postumamente pela Universal Edition em 1935 e revisado por Oswald Jonas em 1956.

6 " $[. .$.$] The expansion of the Schenkerian empire has accelerated since the publication of Free Composition, and among the newly sympathetic$ have been some notable former opponents" (ROTHSTEIN, 1986, p. 9).

7 "I am convinced that the great impact that 'Structural Hearing' had, years ago, was considerable part to its tone, its rhetoric. [...] The organization and comprehensiveness of the book make the student feel that he is in competent hands; while the reassuring tone [...] eases the student's mind as he enters an unfamiliar world" (ROTHSTEIN, 1986, p. 11).
} 
e completado, em certo sentido, pela primeira vez, de tal forma que sua aplicação possibilita o entendimento da música tonal de vários estilos e períodos"8.

A trajetória de Schenker chegou ao Brasil no início da década de 1960, segundo consta no artigo "The Reception and Dissemination of European Music Theories in Brazil", quando o musicólogo George Wasserman esteve nos Cursos de Verão de Teresópolis (RJ), patrocinados pela Pró-Arte 9 . No final daquela década, a pianista, compositora e professora Ester Scliar passou a trabalhar o contorno melódico por graus conjuntos nos Seminários de Música Pró-Arte, no Rio de Janeiro. O artigo conclui que "talvez, conceitos de Schenker de estrutura e coerência na música tonal tenham sido inicialmente transmitidos no Brasil através de Salzer" (ALMADA et al., 2018).

A proposta schenkeriana encontrou seu espaço nas universidades brasileiras desde o surgimento dos cursos de pós-graduação em Música na década de 1970, tendo se acentuada na década de 1980. Creditamos esse fato ao retorno de musicólogos brasileiros que estudaram nos Estados Unidos - como Cristina Capparelli Gerling, Ilza Nogueira e Jamary de Oliveira (cf. ALMADA et al., 2018) - bem como ao reconhecimento de sua abrangência, seja pela identidade com as práticas da performance e da história da composição, seja pela relevância que conquistou junto à área de Música desde a década de 1950. Nas aulas de Análise Musical ministradas por duas pianistas e analistas musicais brasileiras ${ }^{10}$, Professoras Maria Lúcia Pascoal e Adriana Lopes Moreira ${ }^{11}$, a bibliografia tem estado baseada em edições de neo-schenkerianos - desde Felix Salzer (1962 [1952]), até Schmalfeldt (2011), passando por Forte e Gilbert (1982), Neumeyer e Tepping (1992), Meeùs (1993), Moreira (2002), Huff (2010), Fraga (2011) e Cadwallader e Gagné (2011 [1998]), tendo incorporado recentemente o livro publicado por Cristina Gerling e Guilherme Sauerbronn de Barros (2020) e a tese de Renata Coutinho de Barros Correia (2021) ${ }^{12}$. Naturalmente, publicações originais de Schenker são abordadas, bem como artigos com perspectivas específicas, como é o caso de Burkhart (1978), Beach (1983, 1989), Baker (1983), Forte (1984, 1988, 1992), Rothstein (1986), Straus (1987), Agawu (1989), Schmalfeldt (1991), Rink (1993), Dunsby (1999), Straus (2003),

8 "Schenker's pioneer work has been modified, expanded and completed, in a sense, for the first time so that its application to tonal music of all styles and periods can be understood" (MANNES. In: SALZER, 1962 [1952], viii).

9 A atividade dos Cursos de Verão da Pró-Arte em Teresópolis se deu entre 1950 e 1989.

10 "Embora há vinte anos atrás se pudesse falar com segurança de 'compositores-teóricos', estamos menos inclinados a considerar essa conjunção particular como certa no clima intelectual de hoje [1989]". "Whereas twenty years ago one could speak confidently of 'composer-theorists', one is less inclined to take that particular conjunction for granted in today's intellectual climate" (AGAWU, 1989, p. 275).

11 Respectivamente, junto a cursos de Graduação e Pós-Graduação oferecidos pelos Departamentos de Música, da Universidade Estadual de Campinas (UNICAMP, desde 1981) e da Universidade de São Paulo (USP, desde 2004).

12 Essas publicações trazem explanações bem claras a respeito das funções dos diversos recursos envolvidos na elaboração do gráfico schenkeriano em multiniveis. Dentre as citadas, o Glossário de termos schekerianos (GERLING; BARROS, 2020) destaca-se pelo cuidadoso e experiente acesso tanto aos originais de Schenker como a textos referenciais de neo-schenkerianos, externando tanto as reafirmações quanto os contrastes estabelecidos entre eles e trazendo entre os exemplos musicais análises elaboradas pelos próprios autores.

Outro destaque pode ser conferido à publicação de Cadwallader e Gagné (2011), tanto pelo texto que alia didatismo com uma descrição aprofundada e precisa de cada recurso schenkeriano, como pelo caderno de atividades que acompanha o texto escrito, que traz partituras desafiadoramente escolhidas para a prática analítica. 
Dodson e Jonas (2003), Rifkin (2004), Drabkin (2006), Barros e Gerling (2007, 2009), Koslovsky (2010), Temperley (2011) e Barros (2018) ${ }^{13}$.

Nessas aulas, procuramos apresentar a proposta schenkeriana nas diversas dimensões que ampliam a percepção dos músicos para os diferentes enfoques da obra musical analisada. Ao trazerem à tona diferentes níveis de profundidade, estes enfoques provocam no músico analista uma sensação de percepção tridimensional da obra.

Partimos da premissa de que o interesse voltado ao trabalho teórico-analítico de Schenker é, em alguns aspectos, comparável ao interesse que se tem pela obra de grandes compositores $^{14}$ (DRABKIN, 2006, p. 812):

Aquilo que é chamado de "teoria schenkeriana" constitui-se de um conjunto complexo de princípios reguladores que inicialmente pretendiam explicar a música tonal dos séculos XVIII e XIX; é, ao mesmo tempo, uma síntese de muitas tradições, abrangendo o contraponto de Fux, o ensino do baixo contínuo de Carl Philipp Emanuel Bach e a teoria harmônica do final do século XIX. [...] um sistema analítico de imenso poder empírico [...] $]^{15}$ (DRABKIN, 2006, p. 812).

Contudo, sempre que o tema análise schenkeriana entra na pauta de discussões, surgem os que ainda hoje insistem no foco em uma suposta redução da linguagem do objeto para a metalinguagem, da obra para o discurso sobre a obra. Ao desconsiderarem a totalidade da apresentação gráfica em multiníveis, reduzindo-a apenas ao momento de apresentação da Ursatz, são perdidas as interlocuções desta reflexão musical multifacetada com práticas de percepção, intuição analítica, composição e performance. Já a afirmativa de que a notação em um gráfico schenkeriano em multiníveis não representa a duração "é, obviamente, normativamente correta, mas poderia facilmente desviar a atenção das ricas possibilidades abertas por este gráfico", observa o musicólogo ganense Kofi Agawu (1989, p. 290).

Em boa medida, o discurso crítico desabonador é calcado em uma descontextualização das considerações políticas e sociológicas historicamente circunscritas à época desse pianista, teórico e analista musical judeu austríaco, falecido em 1935, no rescaldo da Primeira Guerra Mundial. No artigo Recent Schenker: The Poetic Power of Intelligent Calculation, o pianista e musicólogo britânico Jonathan Dunsby (1999, p. 264) já chamava a atenção para a crítica europeia à retomada estadunidense da proposta schenkeriana ter estado sempre apoiada nos "maneirismos verbais do original". A respeito desses maneirismos, continua vigente a consideração de Agawu (1989, p. 283): evidentemente, "não são mais axiomáticos no clima intelectual de hoje".

13 Observe-se que a proposta schenkeriana manteve-se sendo estudada ininterruptamente, por musicólogos de expressão, desde meados do século XX até os dias atuais.

14 "Indeed, the interest shown in his life's work is, in some respects, comparable to that of some of the twentieth century's leading composers, and in this respect his reputation as a theorist is unequaled" (DRABKIN, 2006, p. 812).

15 "That which is called 'Schenkerian theory' is a complex set of regulatory principles that were initially intended to explain the tonal music of the eighteenth and nineteenth centuries; it is at the same time a synthesis of many traditions, embracing Fuxian counterpoint, the thorough-bass teaching of Carl Philipp Emanuel Bach and late nineteenth-century harmonic theory. [...] an analytical system of immense empirical power. [...]" (DRABKIN, 2006, p. 812). 
Schenker atuou também como crítico musical. Contudo, restringiu-se ao campo artístico, tendo em vista a consciência de sua circunscrição a este domínio. Para a formação teórica de músicos comprometidos com a performance e a composição em profundidade, posicionou-se favorável ao estudo de obras musicais vivas do passado, em detrimento de replicarem treinamentos alheios ao repertório musical:

o cerne da crítica de Schenker aos teóricos de seu tempo é justamente a ausência de gênio ${ }^{16}$ - e de improvisação ${ }^{17}$ - na obra desses autores. Não apenas as análises realizadas a partir das teorias correntes, mas as obras compostas segundo os tratados de composição convencionais são, na visão de Schenker, estruturas mortas, cadáveres desprovidos da chama vital que somente a verdadeira arte do gênio possui.

Schenker [...] [coloca] como o mais elevado propósito musical de seu tempo constatar e revelar a perfeição - a organicidade - das obras primas dos grandes mestres do passado. Sua busca pela conexão das obras primas entre si e de todas elas com o absoluto da arte - absoluto formal que é a própria Ideia - transparece nas palavras finais do artigo sobre a organicidade na fuga: "Com olhos e ouvidos voltados para as profundezas, liguemos eternidade a eternidades!". (GERLING; BARROS, 2009, p. 106, 108-109)

Desde o momento em que Schenker passou a desfrutar de alguma proeminência no cenário musicológico, sua proposta foi acolhida com entusiasmo por uns e rechaçada por outros. Oswald Jonas (In: DODSON; JONAS, 2003, p. 124, 127) sugere que esta polarização seja fruto, sobretudo, de certa propensão à abstração na proposta schenkeriana. Trata-se de uma abstração completamente dependente da experiência prática do analista, que reflita a experiência prática do próprio Schenker, impressa nas entrelinhas de sua proposta. Talvez a necessidade dessa resposta instintiva seja mais responsável pela negação da proposta schenkeriana do que propriamente a retórica politicamente carregada das décadas de 1920 e $1930^{18}$.

Nesse sentido, "valorizar o julgamento e responsabilidades individuais, para afirmar os valores humanos contra os mecânicos, esta é a fonte do tom moralizante e às vezes messiânico que, se não for entendido no contexto, pode ser uma das características

16 "Conforme ensinou Kant, o gênio é a faculdade através da qual a natureza fornece as regras à arte" (GERLING; SAUERBRONN DE BARROS, 2009, p. 101).

170 conceito schenkeriano de improvisação refere-se à "habilidade de um artista em gerar uma abundância de ideias musicais no interior de uma harmonia enxuta. [...] a forma deriva da construção, acumulação e regeneração de grupos dentro de uma tonalidade unificadora (e, portanto, do impulso de improvisação)"; "[...] the ability of an artist to generate an abundance of musical ideas within an economy of harmony. [...] form derives from the construction, accumulation, and regeneration of groups within a unifying tonality (and thus from the improvisatory impulse)" (KOLOVSKY, 2010, p. 60-61, 66). "[...] o todo deve ser criado pela improvisação, se não quiser ser um mero conjunto de partes individuais e motivos de acordo com um conjunto de regras". "[...] the whole must be created by improvisation, if it is not to be a mere assemblage of individual parts and motives in accordance with a set of rules" (SCHENKER 1996 [1926], p. 23 apud KOLOVSKY, 2010, p. 76).

18 "[...] the stigma that was imposed upon it"; "[...] rather is, in the end, the result of practical experience spanning many years, in which pure musical instinct played no less a part than strictly rational thought processes" (JONAS, 1964. In: DODSON; JONAS, 2003, p. 124, 127). 
mais alienantes da escrita de Schenker"19 (COOK, 2007, p. 128). Embora aparente algum mecanicismo, a proposta schenkeriana atinge seu objetivo apenas quando conduz o analista a uma vivência de resgate intuitivo do seu conhecimento musical. Assim sendo, os diferentes níveis schenkerianos correspondem a diferentes níveis de consciência musical acerca da obra analisada.

Não podemos deixar de registrar nossa divergência quanto a posicionamentos contrários à análise por vozes condutoras de obras pós-tonais. No artigo de 1999, Jonathan Dunsby (1999, p. 266) destaca dois autores que se estabelecem nesse sentido. Leslie Blasius (1996) acredita ser prematura a abordagem de Katz, Salzer, Travis, Baker e Straus sobre vozes condutoras pós-tonais e destaca a natureza diferenciada das análises desses autores em relação à proposta original de Schenker. Robert Snarrenberg (1997) concorda com isso e acredita que o pensamento de Schenker não resiste à descontextualização, ou seja, está intrinsicamente ligado ao seu próprio cânone, tempo e lugar.

Naturalmente, estamos cientes de que a proposta original de Schenker é voltada ao repertório tonal cujas bases qualitativas respondem ao seu ideário. Contudo, em um sentido didático, percebemos haver uma resposta qualitativa considerável por parte dos músicos que se mobilizam para interagir com a realização de reflexões e análises motivadas pela proposta teórico-musical de Schenker, sobretudo quando estas se estendem a repertórios para além daqueles presentes nas publicações originais. Um acolhimento dos repertórios de preferência dos estudantes - invariavelmente incluindo obras pré-tonais, pós-tonais e da vertente popular e jazz - favorece uma interlocução da proposta schenkeriana com suas vivências musicais pregressas, redundando em reflexões em um nível musical ao mesmo tempo identitário e aprofundado ${ }^{20}$.

\section{Ensinando a identificação motívica através do contraste entre o motivo schenkeriano e o motivo schoenbergiano}

Cadwallader e Gagné apresentam a proposta schenkeriana a partir de um enfoque em sua singularidade, "por sua habilidade em diferenciar o que é único em uma composição do que é comum a várias peças do repertório tonal"21 (CADWALLADER; GAGNÉ, 2011 [1998], p. 12). Focando inicialmente aspectos exclusivos de cada obra, o livro se inicia pela exposição da análise motívica da Sonata para piano op. 2, n. 1, I, de Beethoven, a partir da análise publicada pelo jovem Schenker no primeiro volume de Der Tonwille (SCHENKER, 2004 [1921-1923]), antes que a teoria da Ursatz atingisse sua forma final.

\footnotetext{
19 "[...] to assert human values against the mechanical, and this is the source of the moralizing and sometimes messianic tone which, if one does not understand it in context, can be one of the most alienating features of Schenker's writing" (COOK, 2007, p. 128).

20 Para que se abra a possibilidade de uma ampliação na perspectiva do estudante frente a uma obra musical consolidada, basta que ele se envolva na análise individual de uma obra musical curta, produzindo um gráfico em multiníveis completo. Uma expansão desse processo para novas análises ou para o estabelecimento de um diálogo com a própria performance ou composição dependerá da identidade e do interesse e cada um. 21 "Schenker's approach is remarkable in its ability to inform us about what is unique about a composition, s well as what that composition shares with other pieces in the tonal repertoire" (CADWALLADER; GAGNÉ, 2011 [1998], p. 12).
} 
Em nossas aulas, costumamos contrastar as considerações de Schenker sobre motivo, conforme expostas por Cadwallader e Gagné (2011 [1998]), com as da conhecida publicação de Schoenberg (2015 [1967]), Fundamentos da composição musical, para que os alunos possam conhecer particularidades do motivo schenkeriano.

Ambos os autores se referem ao motivo como um elemento "germinal" da obra musical, remetendo à ideia evolucionista então vigente. Já a noção de "coerência" é relacionada por ambos a estratégias de construção musical. No entanto, para Schoenberg (2015 [1967], p. 35-36), a coerência decorre do fato de um motivo incluir elementos de todas as figuras musicais subsequentes e estar presente em todas elas - ou seja, pode ser identificado através de sua capacidade de produzir variações, desde as mais próximas até as mais remotas. Schoenberg considera que as variações em desenvolvimento na música tonal desempenham um papel de realizadoras das implicações do motivo inicial (Grundgestalt), atingindo a consumação da ideia musical (Gedanke) (BOSS, 1992, p. 130). Em Schenker, a noção de coerência vem imbuída do sentido de "conexão" e encontra uma ressonância especial em sua visão estrutural (DRABKIN, 2006, p. 829). O agrupamento escolhido para ocupar a posição de motivo precisa ser um padrão que se repete em momentos de articulação estrutural da peça (CADWALLADER; GAGNÉ, 2011 [1998], p. 4), revelando conexões e relações que não são de apreensão imediata. Esse motivo é "sempre o mesmo, mas nunca [está] da mesma maneira"22 (SCHENKER, 2004 [1921-1923], p. 4).

Na Figura 1, os motivos destacados por Schoenberg (2015 [1967], p. 89) estão circulados com a cor lavanda (comp. 1) e o motivo considerado por Schenker (CADWALLADER; GAGNÉ, 2011 [1998], p. 5-6) está demarcado com um retângulo na cor verde (comp. 7-8).
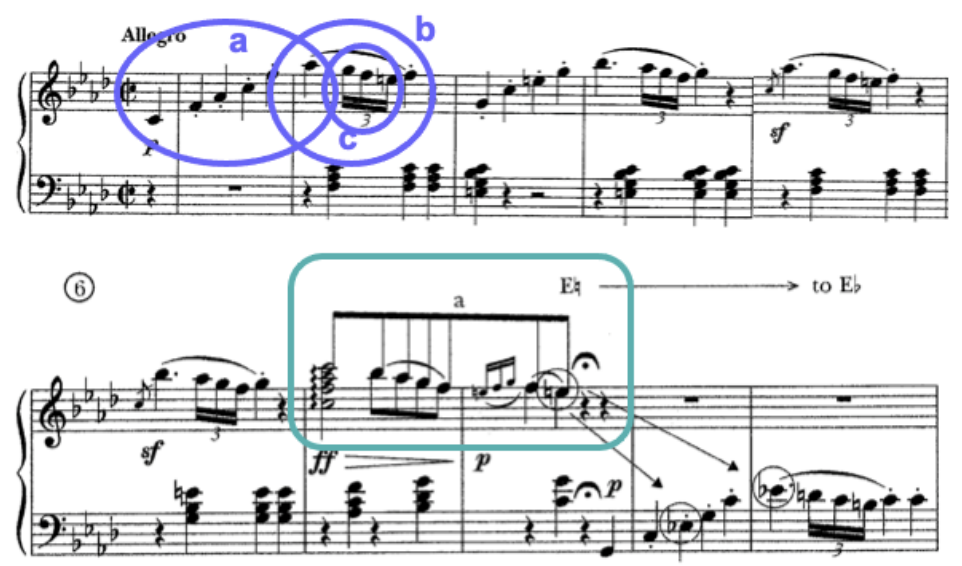

Fig. 1 - Contraste entre os conceitos de motivo para Schoenberg (comp. 1-2) e para Schenker (comp. 7-8). Beethoven, Sonata para piano Op. 2, n. 1, 1, comp. 1-10.

Fonte: Cadwallader e Gagné (2011, p. 5-6, ex. 1.1 e 1.2).

22 "This redeemer will strengthen the immutability and eternal validity of the solutions hitherto achieved - semper idem sed non eodem modo, newly promulgated - and will moreover bring them to universal validity, though only to the extent of man's capacity to accept them" (SCHENKER, 2004 [1921-1923], p. 4). 
Qual é a razão dessa diferença? Schoenberg depreende a unidade de uma composição musical da relação lógica e coerente entre suas partes (sobretudo motivos e temas); Schenker considera os significados e as formas de articulação das partes em relação ao todo. Schoenberg identifica as três ideias musicais formadoras do primeiro tema, que se somarão às ideias musicais do segundo tema, tendo sido ambas amplamente variadas com o intuito da manutenção de uma identidade no nível de superfície do primeiro movimento, mesmo quando variações mais longínquas são exploradas pelo compositor. Este elemento de superfície molda-se às ambientações harmônicas, rítmicas, texturais, timbrísticas, articulares e dinâmicas da obra musical. Schenker, por outro lado, observa nos primeiros compassos desta Sonata uma "energia propulsora", que tem como ponto focal a nota Dó6 ${ }^{23}$ (comp. 7, Fig. 1) suportada pelo acorde arpejado de Fá menor e seguida por um movimento descendente de sexta, que ademais virá a estabelecer um contraste entre a nota Mi (comp. 1-8) e a nota Mib (comp. 9 e seguintes). Na Transição, na Retransição e na Recapitulação, essa sexta estabelece uma ampla conexão (Fig. 2); na Transição e na Exposição do Tema 2, o contraste maior-menor é explorado. Para Schenker, todo esse complexo conceitual assume um significado motívico devido à sua proeminência ao longo do movimento 24 .

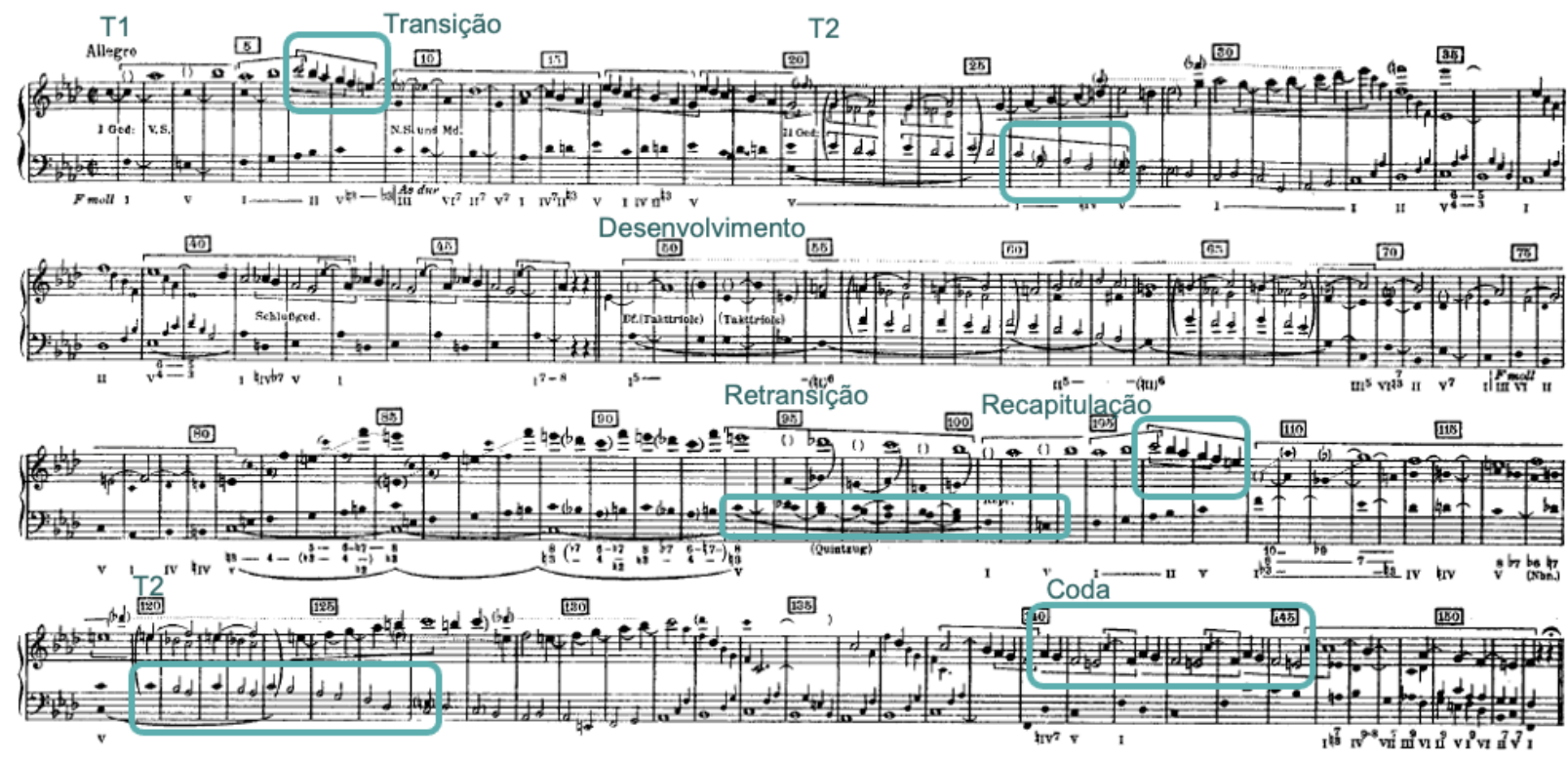

Fig. 2 - Análise de Schenker publicada no volume 1 de Der Tonwille, antes do desenvolvimento do gráfico com multiníveis. Beethoven, Sonata para piano Op. 2, n. 1, I.

Fonte: Schenker (2004 [1921-1923], p. 73).

23 Tendo como referência o Dó central como Dó4.

$24 \mathrm{Sim}$, a Figura 2 traz um exemplo de um jovem teórico analisando a obra de um jovem compositor, ambos deixando à mostra, de maneira ainda embrionária, condutas que futuramente vieram a incorporar estratégias sofisticadas e determinantes para as suas respectivas áreas de atuação. Contudo, didaticamente falando, exemplos dessa natureza tendem a constituir-se como portas de entrada a práticas da composição, da musicologia e da performance. "Há que considerar ainda a ênfase de Schenker no repertório dos séculos XVIII e XIX, base da formação musical do instrumentista erudito. [...], a análise schenkeriana equivale à crítica romântica e tem na interpretação musical (performance) seu modo de apresentação (expositio)" (BARROS; GERLING, 2009, p. 70). 
Em seus primeiros escritos, Ein Beitrag Zur Ornamentik (1908) e Harmonielehre (1906), Schenker associa seu conceito de motivo ao seu conceito de improvisação:

Ele [o motivo] compreende duas partes básicas. A primeira é semelhante à interpretação de Salzer: uma série de ideias curtas e interconectadas formam o tecido musical. Cada motivo inspira naturalmente o seguinte. E essas ideias formam grupos maiores, a que Shenker denomina Gruppenbildung ("construção por grupos"). Conectada com a Gruppenbildung está a segunda parte do impulso improvisatório: isto é, a habilidade de um artista em gerar uma abundância de ideias musicais no interior de uma harmonia enxuta. A harmonia necessita do contexto musical e o conteúdo é agrupado com base na condução harmônica ambos vivem em uma relação simbiótica.

[...] O impulso improvisatório, portanto, fornece um organicismo motívico baseado em um fluxo dinâmico de ideias musicais, ao invés de estar vinculado ao desenvolvimento de uma única célula motívica ${ }^{25}$ (KOLOVSKY, 2010, p. 60-61).

No todo de sua obra, Schenker reconheceu e descreveu algumas repetições de motivos na superfície ${ }^{26}$, mas seu foco recaiu sobre repetições em níveis mais profundos, onde o motivo fica obscurecido por sua elaboração:

Essa repetição "oculta", para usar um dos termos de Schenker, é definida não por sua articulação rítmica, mas por seu conteúdo de alturas, ordenado em relação ao enunciado original, podendo estar com as mesmas alturas ou ser transposto. [...] Schenker, é claro, não é o único teórico a observar a repetição motívica em níveis mais profundos. Encontramos essa ideia expressa ocasionalmente nos escritos de Réti e pelo menos implícita nos de Schoenberg. Mas [...] a ideia de Schenker é muito mais específica, uma vez que, em sua teoria, a seleção de sons em vários níveis, incluindo sons de um motivo, está ligada às regras do contraponto. Ou seja, a escolha não é arbitrária ${ }^{27}(\mathrm{BEACH}, 1989$, p. 6).

25 "It falls into two basic parts. The first is similar to the way Salzer interpreted it: a series of short, interconnected ideas weave to the thread of the music. Each motive naturally inspires the next. These ideas then form larger groups, what Schenker refers to as Gruppenbildung ('group construction'). Connected with Gruppenbildung is the second part to the improvisatory impulse: that is, the ability of an artist to generate an abundance of musical ideas within an economy of harmony. The harmony necessitates the musical content, and the content is grouped based on the needs of the harmony - them live in a symbiotic relationship. [...] The improvisatory impulse thus delivers a motivic organicism based on a dynamic flow of musical ideas rather than the outgrowth of a single motivic cell" (KOLOVSKY, 2010, p. 60-61).

26 Comentários sobre motivos de superfície aparecem "com muito mais destaque nas análises de Schenker de composições individuais do que em seus escritos especificamente teóricos". "Although the existence of motivic parallelism in Schenker is made possible by his concept of structural levels, the idea is not itself a systematic construct. [...] indeed, the idea figures much more prominently in Schenker's analyses of individual compositions than in his specifically theoretical writings" (BURKHART, 1978, p. 146-147).

27 'Such a 'hidden' repetition, to use one of Schenker's terms, is defined not by its rhythmic articulation but by its ordered pitch content in relation to the original statement, which may be at the same level or transposed. [...] Schenker, of course, is not the only theorist to observe motivic repetition at deeper levels. We find that idea expressed occasionally in the writings of Réti and at least implied in those of Schoenberg. But [...] Schenker's idea is far more specific, since in his theory the selection of pitches at various levels, including pitches of a motive, is tied to the rules of counterpoint. That is, the choice is not at all arbitrary" (BEACH, 1989, p. 6). 
Um fragmento da interpretação de 1978 do pianista e musicólogo estadunidense Charles Burkhart, acerca do mesmo primeiro movimento da Sonata para piano op. 2, n. 1, de Beethoven (Fig. 3), foi apresentada à luz de seus estudos sobre a bibliografia completa de Schenker. Nesse fragmento, são projetadas as três primeiras notas do motivo schenkeriano subjacentes à superfície dos 41 compassos iniciais. Observe-se como, através dessas linhas "ocultas" projecionais, o motivo vai generalizando para os demais níveis estruturais em um processo dinâmico de conexão do geral com o particular.

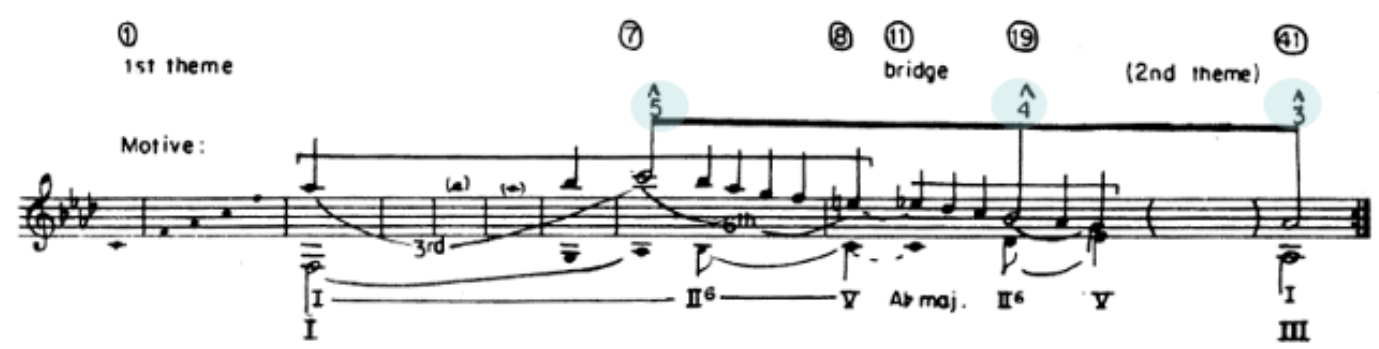

Fig. 3 - Presença mais abrangente do motivo. Beethoven, Sonata para piano Op. 2, n. 1, I.

Fonte: Burkhart (1978, p. 160).

Ao estabelecer uma distinção entre as ideias de motivo e variações (Schoenberg) e repetições "ocultas" (Schenker), Burkhart $(1978$, p. 149, 155) considera uma distinção de grau, em que a primeira preserva uma identidade rítmica, estando tanto o padrão quanto a repetição inteiramente na superfície. Embora essas repetições pudessem assumir a forma de transformações rítmicas simples na superfície, ficando menos evidentes pela ação dessas transformações, "Schenker estava muito mais interessado naquelas que envolviam elementos subjacentes, ou seja, em que o motivo era expresso em diferentes níveis estruturais" 28 (BURKHART, 1978, p. 146). A Figura 4 traz mais um exemplo de Burkhart, novamente com foco nas repetições "ocultas" de Schenker:

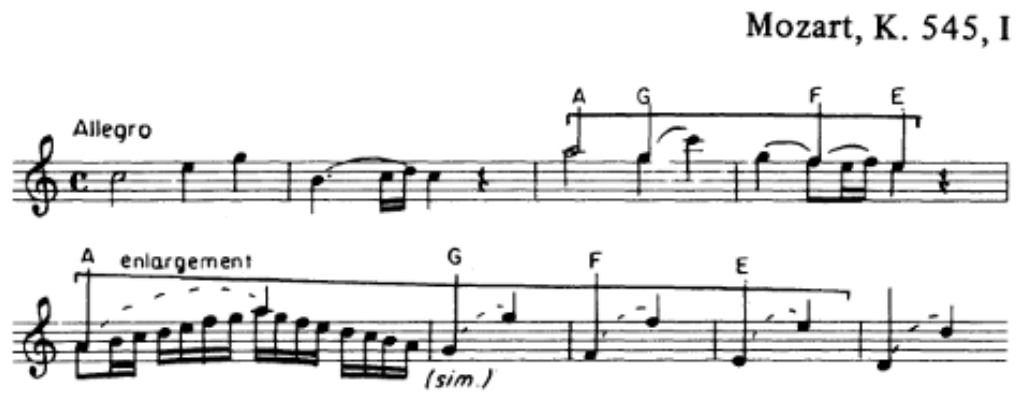

Example 1a (after Jonas)

Fig. 4 - Repetições motívicas "ocultas". Mozart, Sonata para piano K. 545, I.

Fonte: Burkhart (1978, p. 148).

28 "While these repetitions could take the form of simple rhythmic transformations on surface, Schenker was much more interested in those that involved subsurface elements, that is, in which the motive was expressed on different structural levels" (BURKHART, 1978, p. 146). 
Assim, o ponto de partida de Schenker se configura como "uma teoria da estrutura tonal que explica tanto a melodia quanto a harmonia e a interação entre ambas" (BURKHART, 1978, p. 146). Uma extensão desse raciocínio inicial de Schenker pode ser verificada em análises de obras pós-tonais. O teórico musical Joseph Straus "sugere um 'modelo associativo' pelo qual as notas separadas no tempo podem ser relacionadas por meios contextuais (por exemplo, registro, timbre, dinâmica e assim por diante)"29 (BEACH, 1989, p. 4).

Para a formação de sua proposta associativa (Fig. 5), inicialmente Straus (1987, p. 4-8) confirmou que uma formação correlata a um motivo pode ocupar contextualmente uma função correlata a uma consonância, permitindo projeções em pequena escala. Contudo, ao tentar completar os diferentes significados de um gráfico em multiníveis, Straus chegou a um dilema: essas "consonâncias" não podem ser hierarquizadas, portanto não podem atingir profundidades mais amplas nos termos prolongacionais schenkerianos. Por outro lado, Straus observou que "afirmações significativas" podem ser obtidas no nível do plano intermediário se as associações de longo alcance forem associativas, ao invés de prolongacionais. A sistematização da Teoria de Conjuntos ${ }^{30}$ emprestou a essas formações "uma integração motívica em todos os níveis estruturais" 31 :

A música pós-tonal pode imitar a aparência de extensões prolongacionais sem usar uma voz condutora verdadeiramente prolongacional. Nessas situações, é fundamental não se deixar seduzir pela referência tonal para aplicar aspectos anacrônicos da teoria tonal. [...] Isso é explicado de forma mais significativa em termos das associações contextuais de cada peça ${ }^{32}$ (STRAUS, 1987, p. 15).

29 "Straus [...] suggests an "associational model" by which notes separated in time may be related by any number of contextual means (for example, register, timbre, dynamics, and so forth)" (BEACH, 1989, p. 4).

30 "[...] a teoria dos conjuntos de classes de alturas. Eu a uso aqui por sua precisão na identificação e comparação de harmonias. Ela fornece informações inequívocas sobre o intervalo que compõe qualquer sonoridade e coloca essa informação dentro de um quadro sistemático". "[...] pitch-class set theory. I use it here because of its precision in identifying and comparing harmonies. It provides unambiguous in-formation about the intervallic make-up of any sonority and places that information within a systematic framework" (STRAUS, 1987, p. 20).

31 "[...] as formulações de Schenker têm papel preponderante na 'teoria dos conjuntos' ou Pitch Class Analysis (Forte, 1973) da música pós-tonal, nas teorias rítmicas propostas por Cooper e Meyer (1956) e nas teorias generativas propostas por Jackendoff e Lehrdahl (1984). Nas mãos de eminentes teóricos, existem adaptações do conceito de prolongação para várias manifestações musicais tonais e pós-tonais, incluindo-se estudos de jazz e de outras vertentes da música popular. É altamente significativo o número de publicações, livros textos, periódicos, e materiais didáticos baseados nos princípios schenkerianos" (GERLING; BARROS, 2020, p. 2).

32 "Post-tonal music may mimic the appearance of prolongational spans without using truly prolongational voice leading. In such situations, it is crucial not to be seduced by the tonal reference in to applying anachronistic aspects of tonal theory. [...] it is more meaningfully explained in terms of the contextual associations of this particular piece" (STRAUS, 1987, p. 15). 

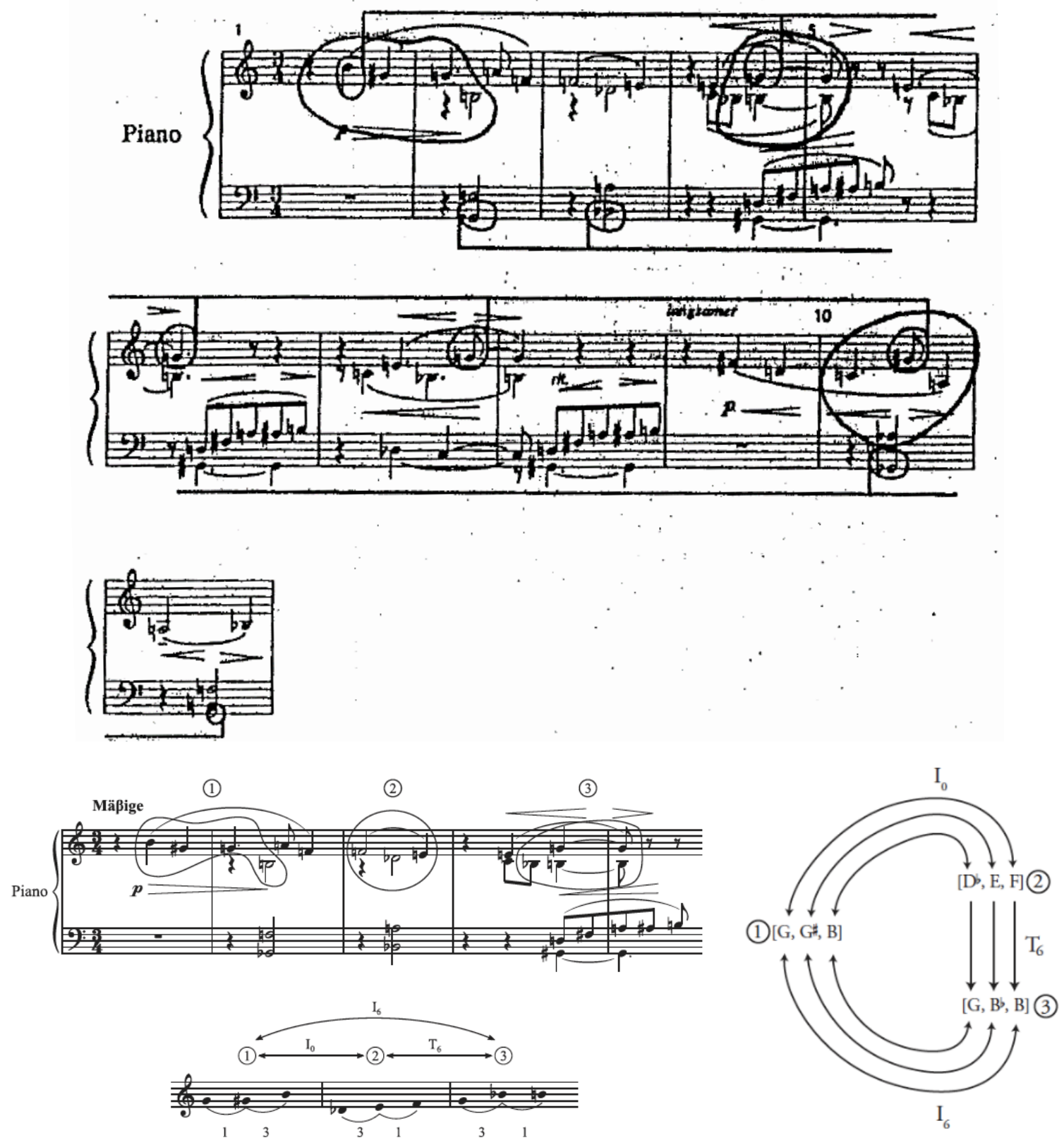

Fig. 5 - Conjuntos formados a partir do pressuposto associativo de Joseph Straus.Schoenberg, Piano piece, op. 11 , n. 1. Fonte: Straus (2003, p. 5; 2016, p. 57)

\section{Música tonal como um jogo de padrões harmônicos? 0 acorde gra- matical e o significado harmônico do acorde}

Ao longo de toda a publicação, Salzer (1962 [1952], p. 10-14, 47, 86) enfatiza uma diferenciação fortemente valorizada por Schenker, entre a gramática do acorde - um meio puramente descritivo de registro e rotulação de cada acorde e sua relação com os diferentes centros tonais, importante apenas como um pré-requisito e não como um fim em si mesmo - e o significado do acorde - o propósito específico e arquitetônico de um acorde no interior de 
uma ideia musical e dependente da finalidade e da direção do movimento. Cadwallader e Gagné (2011 [1998], p. 41-42) reservam o termo acorde para a primeira situação e o termo harmonia para a segunda.

O significado de um acorde com a mesma denominação gramatical depende de seu posicionamento no interior desse movimento ${ }^{33}$. Cadwallader e Gagné (2011 [1998], p. 41-42) optam por explorar a forma mais elaborada do movimento tonal essencial I-V através das classes harmônicas T-Int-D-T34. No enfoque harmônico das análises de obras musicais, são observados os movimentos contrapontísticos de prolongamento e expansão junto às classes harmônicas subjacentes. Nesse contexto, um acorde de quinto grau (V), por exemplo, reveste-se de diferentes sentidos, sendo um deles o significado de dominante. Na Figura 6 , o $V$ do compasso 4 articula a frase com 4 compassos, mas no movimento em larga escala, 0 $\mathrm{IV}_{6}$ (comp. 5-7) mostra que $\circ \mathrm{V}$ do comp. 4 é um ponto focal intermediário entre o I-V, uma dominante divisória "que divide o espaço (Tonraum) governado pela tônica, expandindo-a" (CADWALLADER; GAGNÉ, 2011 [1998], p. 56). O V com significado de dominante cadencial é atingido no compasso 8 .
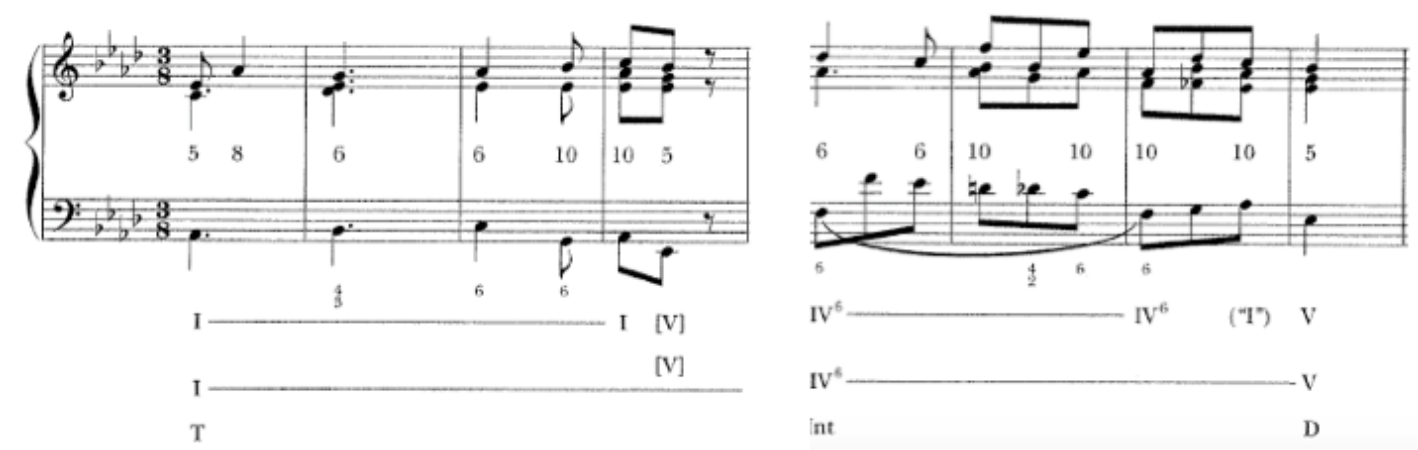

Fig. 6 - Diferentes significados do acorde de quinto grau.Beethoven, Sonata para piano, op. 26, l, comp. 1-8, redução por acordes de Cadwallader e Gagné.

Fonte: Cadwallader e Gagné (2011, p. 55, ex. 3.14).

Essa diferenciação é essencial ao aprendizado do estudante que entende a harmonia como sendo um jogo de padrões, esquecendo-se de percebê-la como resultante dos movimentos horizontais, que por sua vez elaboram um fluxo de condução - de maneira única para cada obra musical.

33 Ao longo do livro Strucutral hearing, Salzer (1962 [1952]) volta-se às seguintes designações de acordes: acorde de passagem (P); acorde-bordadura (em inglês, N de neighbor); acorde-bordadura incompleto (IN); acorde-bordadura de passagem (em inglês, NP de neighbor-passing chord); dominante divisória (D) que causa uma interrupção ( || ); acorde contrapontístico-estrutural (em inglês, CS); acorde ornamental (Em, embellishing chord); acorde de ênfase melódica.

34 No contexto T-Int-D-T, a abreviação "Int" se refere à classe harmônica intermediária (Int class), ou seja, às diversas harmonias intermediárias que podem ocupar o espaço harmônico entre a região das harmonias que compõem a classe harmônica tônica ( $T$ class) inicial e a região das que compõem a classe harmônica dominante ( $D$ class). As harmonias intermediárias ornamentam/elaborarm, expandem ou prolongam a região da classe tônica inicial. No livro Analysis of tonal music: a schenkerian approach, Cadwallader e Gagné (2011 [1998]) focam, além dessas três classes harmônicas, os conceitos: tônica aparente, dominante divisória, expansão, elaboração, desdobramento, notação gráfica (ligaduras pontilhadas, chaves, linhas, setas, barras cruzadas etc.), padrões intervalares, interrupção de período, linha fundamental (Urlinie), arpejamento do baixo (Bassbrechung), representação da estrutura mais fundamental (Ursatz), movimento ascendente inicial, movimento para e a partir de uma voz interna, dentre outros recursos. Ao final, após contrastar conceitos sobre estrutura e forma, são apresentadas análises de obras musicais a uma, duas e três partes, Rondós, Sonatas e planos tonais em larga escala. 
A compreensão de Schenker, de que as obras tonais se constituem enquanto desdobramentos do acorde de tônica, que contém os elementos essenciais do movimento harmônico, leva à distinção de harmonias mais e menos essenciais ao contexto da obra que está sendo analisada:

Da mesma forma, as notas de uma melodia podem ser descritas como essenciais ou como transitórias. Além disso, a noção de essencial versus passagem, de harmônico versus não harmônico, se aplica não apenas à superfície da música, mas também informa os níveis mais profundos: uma harmonia pode ser essencial em um nível, mas transicional em outro, uma nota de passagem em um nível pode ser o início de uma "progressão linear" importante em outro ${ }^{35}$ (DRABKIN, 2006, p. 816).

\section{Ensinando contraponto através da identificação do significado do movimento das vozes condutoras em obras musicais}

No livro The Schenker Project, o musicólogo e crítico musical Nicholas Cook (2007, p. 103104, 118-121, grifos nossos) contextualiza os primeiros estágios do projeto de Schenker no âmbito da crítica contemporânea artística vienense. Partindo do pressuposto de que alguns padrões de pensamento teórico "são tecidos na estrutura da experiência cotidiana", Cook constata uma identificação "do progresso com a eliminação do ornamento" no ambiente artístico de Viena à época de Schenker - com reflexos na arquitetura, nas artes visuais e na crítica musical. Nesse ambiente, o detalhe remetia "à força potencialmente contracultural"36.

O "modernismo ético" vigente em Viena rechaçava a frivolidade da ornamentação arquitetônica e, embora esse "modernismo como uma atitude de espírito não se traduza de maneira muito direta em preferências estéticas", esse conceito permeou o projeto schenkeriano inicial. Schenker, no entanto, estabelece uma distinção entre os ornamentos e valoriza aqueles que estabelecem uma relação dialética com o todo, considerando sempre que o que não é essencial em um nível pode se tornar essencial em outro nível (COOK, 2007, p. 128-134) ${ }^{37}$.

Nesse modernismo no qual o conservadorismo de Schenker esteve imerso, o acessório subordina-se ao principal, o primeiro plano reverbera o plano de fundo, as janelas periféricas posicionam-se em relação à sua função junto ao cômodo arquitetônico que atende (COOK, 2007, p. 128-134), o traçado essencial das artes visuais traduz-se enquanto voz condutora musical.

\footnotetext{
35 "Similarly, the notes of a melody can be described as either essential or transitional. Moreover, the notion of essential versus passing, of harmonic versus non-harmonic, applies not only to the surface of the music but informs the deeper levels, too: a harmony might be essential at one level but transitional at another, a passing note at one level might be the start of an important 'linear progression' at another" (DRABKIN, 2006, p. 816).

36 "[...] are woven into the fabric of everyday experience"; "the identification of lack of ornamentation with progress"; "as a potentially countercultural force" (COOK, 2007, p. 118, 104).

37 "This ethical or moral modernism is an equally integral dimension of the Schenker project"; "modernism as an attitude of mind does not translate in any very direct way into aesthetic preferences" (COOK, 2007, p. 128).
} 
Subjacentemente a uma linha melódica tonal, por mais angulosa que esta possa ser, é sempre possível encontrar movimentos por graus conjuntos em que cada nota estabelece uma relação única com as demais, gerando a maior continuidade melódica possível.

Schenker usou o termo fluxo melódico (flissender Gesang) para descrever este equilíbrio e estabilidade, e o termo Urlinien para se referir a estas linhas subjacentes (cf. CADWALLADER; GAGNÉ, 2011 [1998], p. 17, 34). Variadas são as técnicas de elaboração melódica, estendendo-se das ornamentações aos prolongamentos e às melodias polifônicas, por exemplo (cf. GERLING; BARROS, 2020). Nas abordagens schenkerianas, "os termos 'contraponto estrito' e 'contraponto livre' deveriam ser substituídos por 'contraponto elementar' e 'contraponto elaborado'. Desse modo ficaria evidente a unidade e a continuidade do processo composicional" (SALZER; SCHACHTER, 1969, p. xix apud BARROS; GERLING, 2009, p. 93). "Tomando emprestados os termos de Schenker de 'Weg mit dem Phrasierungsbogen', unidade não precisa implicar uniformidade, mas pode englobar diferença"38 (COOK, 2007, p. 135).

O estabelecimento de duas linhas melódicas, uma em região mais grave, outra em região mais aguda, coloca em interlocução as forças geradoras de ambos os fluxos melódicos e dessas forças concorrentes são estabelecidas relações de direcionamento, bem como a formação de uma força motriz que conduz o movimento musical. Vistas sob o enfoque tonal, as linhas melódicas podem ser entendidas como sendo elaborações do caminho traçado pelas vozes condutoras e pelas forças propulsoras das diversas consequências da condução harmônica tonal. Uma maneira de se escutar e entender princípios fundamentais polifônicos das estruturas musicais é através da identificação das estratégias contrapontísticas imanentes à formação de obras musicais.

Schenker estimula uma distinção entre ornamentos mais próximos das vozes condutoras daqueles menos autônomos e mais próximos da superfície (COOK, 2007, p. 129-131). Da segunda espécie contrapontística emergem as primeiras nuances do aprofundamento em multiníveis formador da proposta schenkeriana ${ }^{39}$. O exemplo na Figura 7 traz uma distinção entre dois diferentes tipos de notas de passagem, a mais estrutural corresponde à nota Si que dá suporte a um acorde de passagem, a mais local corresponde ao Fá da voz superior. Sendo assim, as duas notas com função aparentemente igual ocupam níveis estruturais diferentes.

38 "To borrow Schenker's terms from 'Weg mit dem Phrasierungsbogen', unity need not entail uniformity, but can encompass difference" (СОOK, 2007, p. 135).

39 Da primeira espécie, Cadwallader e Gagné (2011 [1998], p. 23-34) destacam o senso de movimento em direção a um ponto focal, decorrente da alternância entre dissonâncias e consonâncias, com os saltos sendo associados à produção de tensão e os graus conjuntos descendentes à dispersão de tensão (Fig. 4). Na segunda espécie o interesse recai sobre o tempo fraco, provendo naturalmente o movimento rítmico da linha melódica e conectando tanto dois diferentes registros ou vozes, como as sucessivas consonâncias que ocupam os tempos fortes. Essas conexões podem ser notas de passagem (P), dissonantes ou consonantes, que conduzem adiante a progressão melódica. 0 ritmo mais rápido da terceira espécie permite a ornamentação de uma única nota, prolongando-a e retendo o movimento da linha melódica, ao invés de conectar duas notas diferentes. A quarta espécie produz a suspensão e o fato de a nota de resolução estar no tempo fraco do compasso denota que o significado harmônico de uma nota não coincide necessariamente com sua posição métrica, denotando que que os princípios de ritmo, metro, contraponto e harmonia agem paralelamente, esporadicamente encontrando uma confluência. 

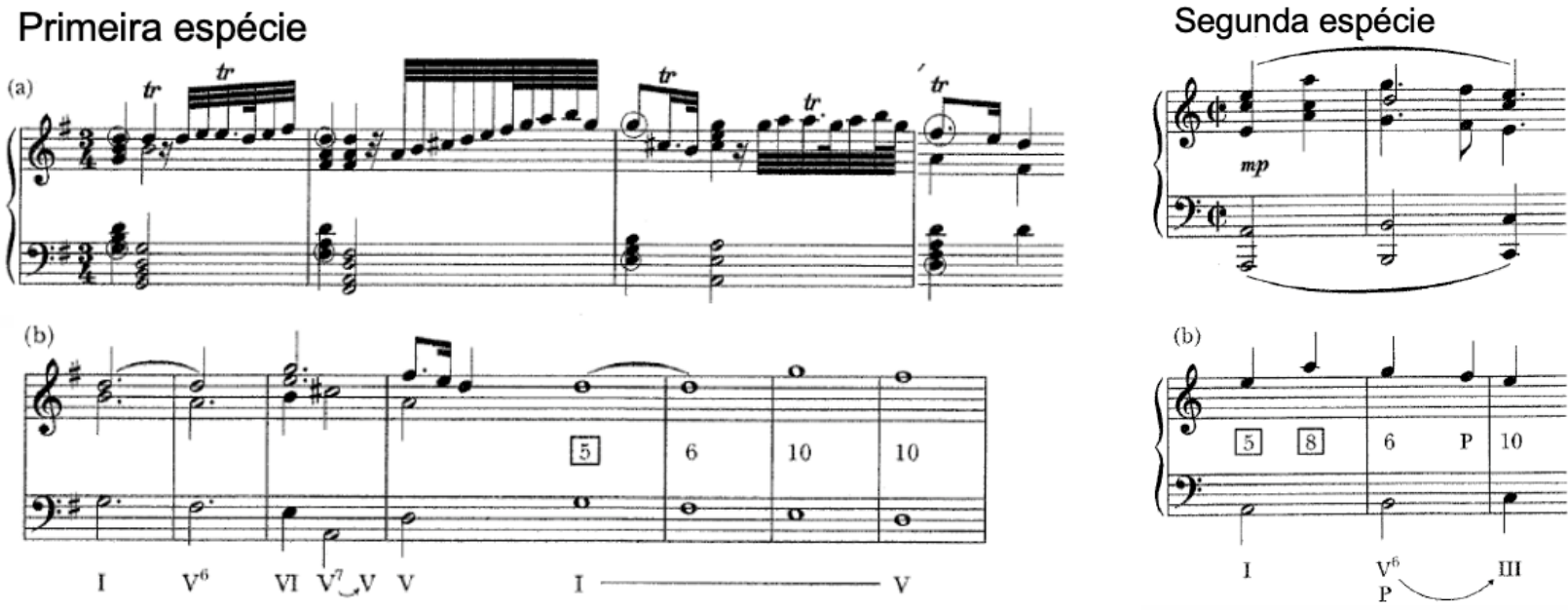

Fig. 7 - Ensino das duas primeiras espécies de contraponto com base na proposta schenkeriana: da obra musical à escuta das vozes e destas às diretrizes do contraponto.

Fonte: Cadwallader e Gagné (2011, p. 25 e 28, ex. 2.8 e 2.10).

A identificação das linhas de condução é inestimável ao performer, tanto para o traçado de um direcionamento da execução como para a memorização da obra. E essa estratégia não precisa se restringir ao repertório tonal, tampouco às obras dos vinte e dois compositores analisadas por Schenker:

Em Harmony, há obras de Johann Sebastian e Carl Philipp Emanuel Bach, Beethoven, Berlioz, Brahms, Bruckner, Chopin, Handel, Hassler, Haydn, Liszt, Mendelssohn, Mozart, Scarlatti, Schubert, Schumann, Richard Strauss, Sweelinck e Wagner. O primeiro volume de Counterpoint deixa Berlioz, Hassler, Scarlatti e Sweelinck e adiciona Graun, Wolf, Smetana e Couperin. Essa lista muda notavelmente, no entanto, em Free composition. Schenker adiciona exemplos únicos de Clementi, Crüger, Des Prez e Paganini, bem como vários exemplos de Johann Strauss, tanto o primeiro como o segundo. No entanto, ele omite os modernistas do século XIX de seu novo cânone: Berlioz, Bruckner, Liszt, Smetana, Richard Strauss e Wagner ${ }^{40}$. (BLASIUS, 1996, p. 99)

No livro Structural Hearing, Felix Salzer (1962 [1952]) interpreta a técnica de análise por vozes condutoras desenvolvida anteriormente por Schenker e amplia o repertório ao incluir

40 "Como os dois últimos compositores listados acima assumem um papel significativo em Harmony e Counterpoint I, sua ausência de Free Composition é particularmente notável. Pode-se [...] simplesmente ler um subtexto político neste movimento [...]. Pode-se falar também de Schenker, ao confundir a tecnologia das novas ciências musicais com esse modernismo, reafirmou a autoridade do cânone como ato de resistência a essas ciências". "Harmony cites works of Johann Sebastian and Carl Philipp Emanuel Bach, Beethoven, Berlioz, Brahms, Bruckner, Chopin, Handel, Hassler, Haydn, Liszt, Mendelssohn, Mozart, Scarlatti, Schubert, Schumann, Richard Strauss, Sweelinck, and Wagner. The first volume of Counterpoint drops Berlioz, Hassler, Scarlatti, and Sweelinck and adds Graun, Wolf, Smetana, and Couperin. This roster changes tellingly, though, in Free Composition. Schenker adds single examples of Clementi, Crüger, Des Prez, and Paganini as well as multiple examples of the elder and younger Johann Strauss. Yet he omits the nineteenth-century modernists altogether from his new canon: Berlioz, Bruckner, Liszt, Smetana, Richard Strauss, and Wagner. As the last two composers listed above take on a significant role in Harmony and Counterpoint I, their absence from Free Composition is particularly striking. One might, again, most simply read a political subtext into this move [...], one might also speak of Schenker, as he conflates the technology of the new musical sciences with this modernism, reasserting the authority of the canon as an act of resistance against these sciences" (BLASIUS, 1996, p. 99). 
obras do Renascimento e do século XX. As ideias dos prolongamentos apresentam os elementos que elaboram a direção determinada pela estrutura e da apresentação em gráficos por multiníveis são mantidas, mas os gráficos de Salzer (Fig. 8) não são tão rigorosos como os de Schenker ${ }^{41}$. Certamente, foi prioritária a acomodação das ideias presentes em obras cuja concepção não está completamente atrelada aos valores tonais.
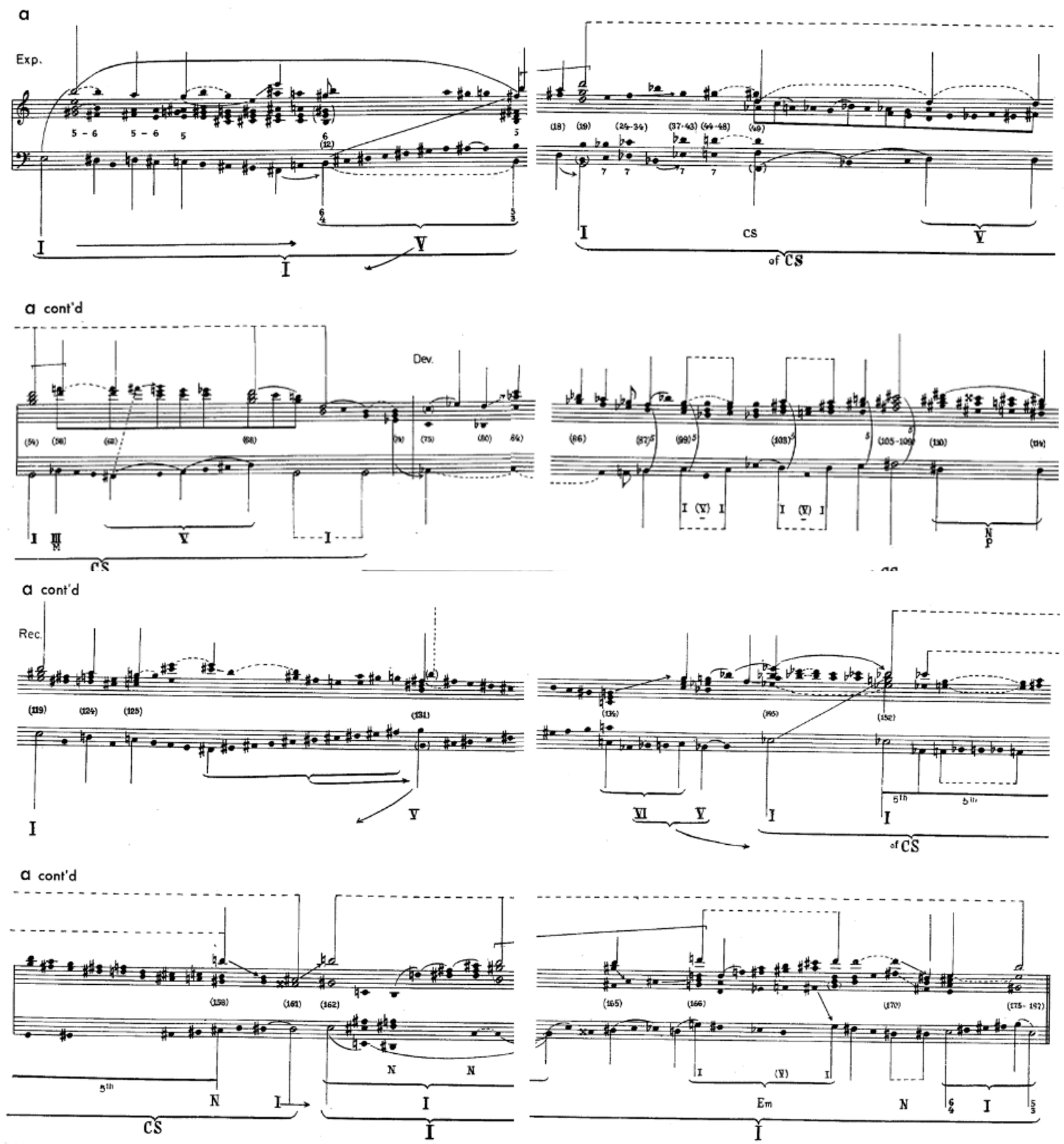

41 No artigo de 1987, Straus oferece uma opção (associativa) que considera alternativa à de Salzer (prolongacional). No entanto, neste momento atual em que a complementaridade de recursos tem se apresentado como estratégia analítica predominante, não as consideramos excludentes e entendemos que se possam optar pela que melhor responder aos anseios da obra sob análise. 


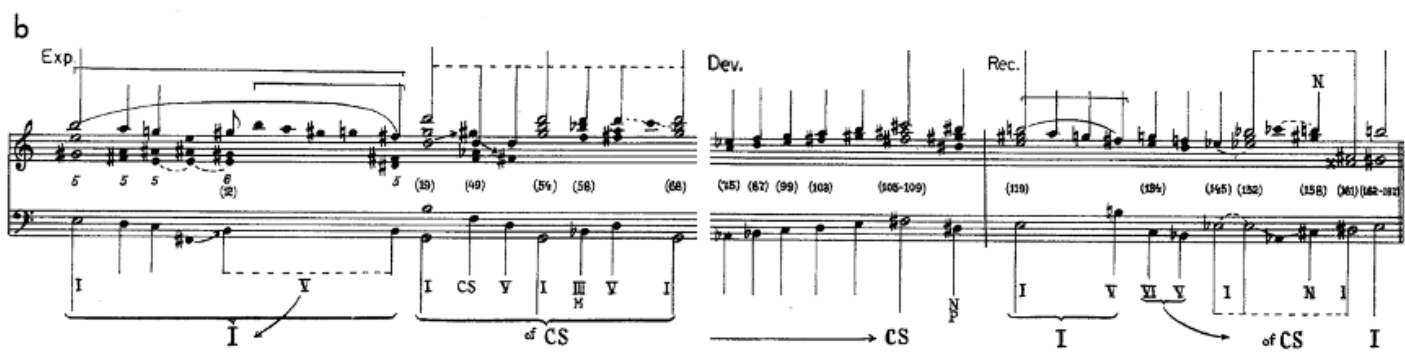

C

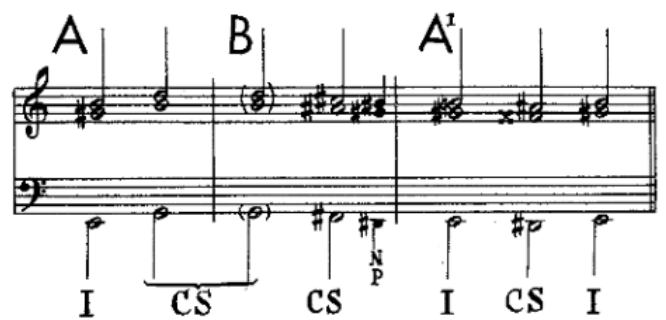

Fig. 8 - Abertura da proposta prolongacional schenkeriana para repertórios não tonais, desde meados do século XX. Bartók, Concerto para piano n. 3, I, na análise de Felix Salzer.

Fonte: Salzer (1962 [1952], p. 258-262, ex. 480).

Ao prescindir do conceito harmônico tonal organicista de Schenker, não contemplando os domínios de uma Ursatz, a audição estrutural de obras pré e pós-tonais proposta por Salzer "ofereceu uma crítica radical à estética e, de fato, aos fundamentos acústicos da teoria de Schenker"42 (DUNSBY, 1999, p. 264). Após a abertura promovida por Salzer, o grupo de comentadores de Schenker se expandiu, passando a abrager "schenkerianos ortodoxos e não ortodoxos, neo-schenkerianos, construcionistas estritos, pós-schenkerianos e muitos

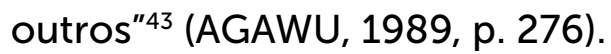

Em nossa experiência percebemos que tanto a análise formal como a análise estrutural schenkeriana são intimamente vinculadas à construção de uma performance, não havendo nessa relação, atualmente, um caráter prescritivo. Sobre a relação entre forma e estrutura, Schenker (apud CADWALLADER; GAGNÉ, 2011, p. 208-210) considerava que as formas emergiam do nível estrutural, tornando-se aparentes no nível externo final e que "a progressão indivisível da linha fundamental gera a ruptura indivisível"44 (SCHENKER, 1979 apud CADWALLADER; GAGNÉ, 2011, p. 208). Contudo, uma análise mais abrangente pode considerar que as interações entre estrutura, design e prolongamentos harmônicos produzem padrões formais, e que essas interações podem não ser coincidentes - por exemplo, formas organizadas a duas e três partes podem se desenvolver no interior de uma estrutura em uma parte.

\footnotetext{
42 "Salzer's (Salzer 1962), in contrast, offered a radical critique of the acoustic foundations of Schenkerian theory" (DUNSBY, 1999, p. 264).

43 "Among the growing fold one finds orthodox and unorthodox Schenkerians, neo-Schenkerians, strict constructionists, post-Schenkerians and a host of others. One sure way to identify them is by their notational stripes." (AGAWU, 1989, p. 276).

44 "The undivided progression of the fundamental line generates undivided ruption" (SCHENKER, 1979 apud CADWALLADER; GAGNÉ, 2011, p. 208).
} 
No livro In the process of becoming, a experiente pianista, esteta e analista musical Janet Schmalfeldt (2011) reúne artigos que vêm sendo publicados por ela desde 1985. Apoiada por uma compreensão aprofundada de ideias e conceitos formulados por Adorno e Dahlhaus acerca da obra de Beethoven, retoma o repertório tonal e toma a liberdade de inserir no gráfico schenkeriano um elemento gráfico $(=>)$ que reflete o conceito filosófico de devir musical, em que, p.ex., uma passagem inicialmente interpretada como Introdução vai sendo impregnada de outros elementos ao longo da escuta da obra musical e, constantemente rememorada e contrastada com estes, sendo reinterpretada como Tema Principal. Com isso, Schmalfeldt expressa graficamente aspectos musicais que ocorrem ao longo do tempo da escuta da obra, bem como aspectos da escuta interna, da imagética auditiva e da reflexão informada que ocorrem em paralelo a esta. Para embasar qualitativamente a sua proposta, Schmalfeldt discute a respeito de aspectos da teoria da forma, com ênfase na formação de sentenças em obras do Classicismo e do Romantismo. Como resultado, o gráfico em multiníveis de Schmalfeldt reflete uma interlocução entre estrutura, forma e devir (Fig. 9).

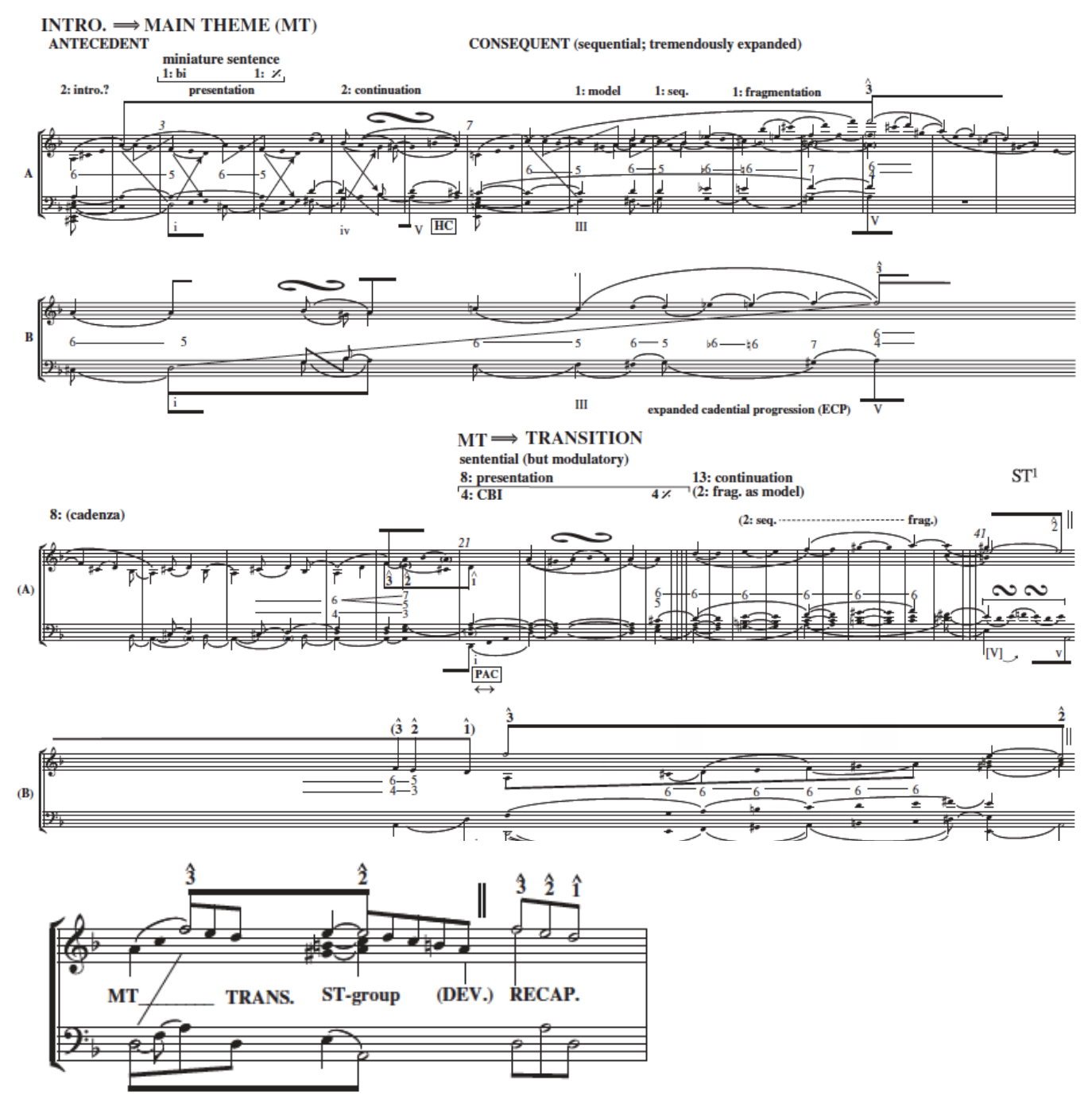

Fig. 9 - Interlocução entre estrutura, forma e devir filosófico no gráfico em multiníveis de Schmalfeldt (2011). Beethoven, Sonata para piano op. 31, n. 2, I, níveis externo e intermediário dos comp. 1-63 e nível fundamental do movimento completo.

Fonte: Schmalfeldt (2011, p. 39, 40 e 44, ex. 2.1 e 2.3). 
Voltando-se a abordagens que colocam em diálogo as configurações horizontais em larga escala e os componentes mais locais, bem como considerando sua contribuição ao estabelecimento da forma e da estrutura musicais, Allen Forte (1988) combina estratégias da fase inicial de Schenker com a abordagem por conjuntos para a análise de obras compostas no final do século XIX e início do século XX (Fig. 10).

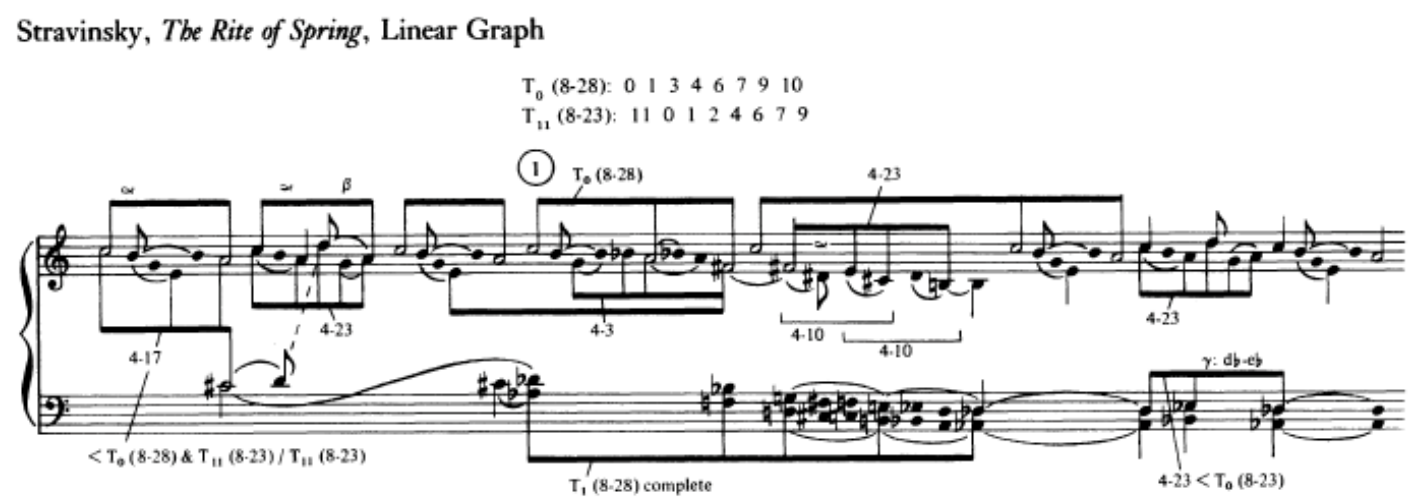

Fig. 10 - Gráfico linear de Allen Forte. Stravinsky, A Sagração da Primavera: Introdução.

Fonte: Forte (1988, p. 321, ex. 1).

Desde que o repertório e a rigidez gráfica foram abertos por analistas neo-shenkerianos ${ }^{45}$, como é o caso de Salzer (1962 [a952]), Forte (1988) e Schmalfeldt (1985 e seguintes), recursos schenkerianos passaram ser usados mais livremente, tanto em análises conceitualmente mais próximas a Schenker, como em análises que requereram adequações. Tomamos como exemplos a análise da Canção op. 2, no. 4, Warm die Lüfte, de Alban Berg (Fig. 11), apresentada por David Huff (2010) para conclusão do Mestrado realizado junto à University of North Texas (UNT), nos Estados Unidos; e a análise da canção Disclosure (1921), de Charles Ives (Fig. 12), apresentada pelo estudante de composição Gabriel Duarte da Silva junto à disciplina Estudos Especiais IV, ministrada por Eliane Tokeshi no curso de Graduação em Música da Universidade de São Paulo (USP), Brasil, em 2019.

A análise de Huff (Fig. 11) é baseada no que o autor denomina acorde estrutural primário (P), um conjunto formado a partir de intervalos de quinta sobre a nota Si. A dualidade entre $3 m-3 M$ reflete a dualidade inerente à canção. Harmonias secundárias (S) e transposições (T) do acorde estrutural primário estabelecem um prolongamento (HUFF, 2010, p. 56-69). Colocando lado a lado a análise apresentada na Figura 11 e a partitura, pode-se ouvir claramente a estrutura por quintas originária dos desdobramentos do acorde primário, os prolongamentos levados a cabo pelas harmonias secundárias, breves aparições de trítonos (nos comp. 7-9) e uma voz condutora cromática ascendente na linha melódica. Assim, um gráfico em multiníveis pode sensibilizar o ouvinte para uma escuta ampliada.

45 No livro A Guide to Musical Analysis, Nicholas Cook (1987, p. 27) registra o termo neo-Schenkerism, ao comentar a respeito de seu uso corrente na década de 1980. 

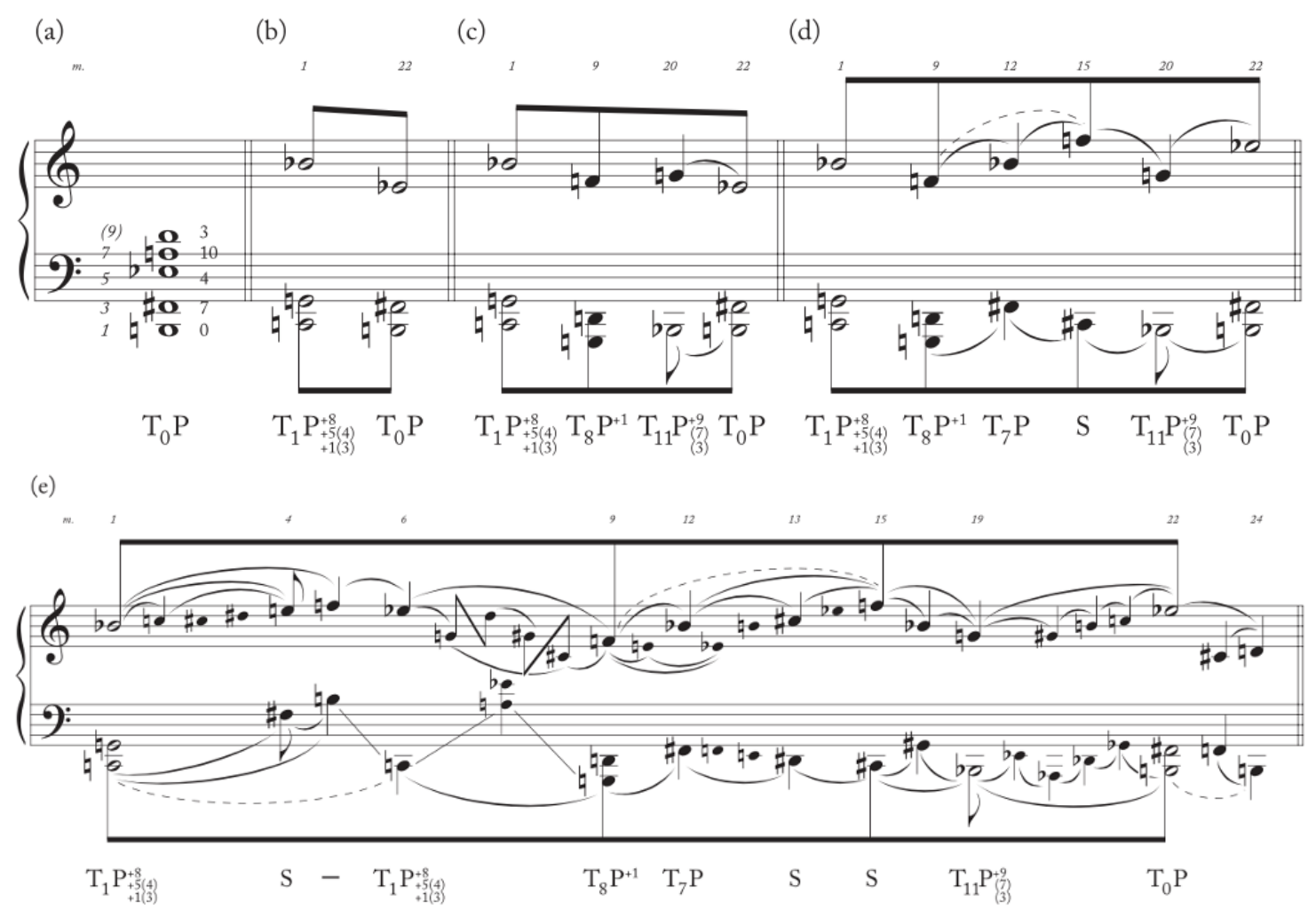

Fig. 11 - Abertura da proposta schenkeriana para repertórios não tonais. Berg, Warm die Lüfte, na análise dos níveis estrutural e intermediários, por David Huff, UNT.

Fonte: Huff (2010, p. 63).

Em sua primeira experiência junto à proposta neo-schenkeriana, Gabriel Duarte incorpora ao gráfico por multiníveis cifras próprias de sua experiência prática junto ao repertório jazzístico do século $X X$, possibilitando a visualização de um contraste entre ambas as propostas (Fig. 12). Essa estratégia imbuiu-lhe de uma conscientização qualitativa sobre toda a gama de movimentos texturais intrínseca à obra, ausente em sua abordagem anterior por acordes cifrados. A abertura da disciplina para obras pós-tonais aproximou a prática schenkeriana da estética composicional do próprio estudante, do que decorreu a escolha da obra de Charles Ives. Nesse sentido, as descontextualizações do original de Schenker, decorrentes da necessidade de adequação de suas ideias ao repertório pós-tonal e à pluralidade de vivências dos estudantes, redundaram em um foco nos elementos gráficos capazes de mostrar os movimentos lineares mais essenciais da obra (Fig. 12), revestindo a sucessão harmônica de um significado linear, de estratégias composicionais subjacentes e de elementos estruturais de longo alcance anteriormente pouco evidentes à percepção do estudante. 

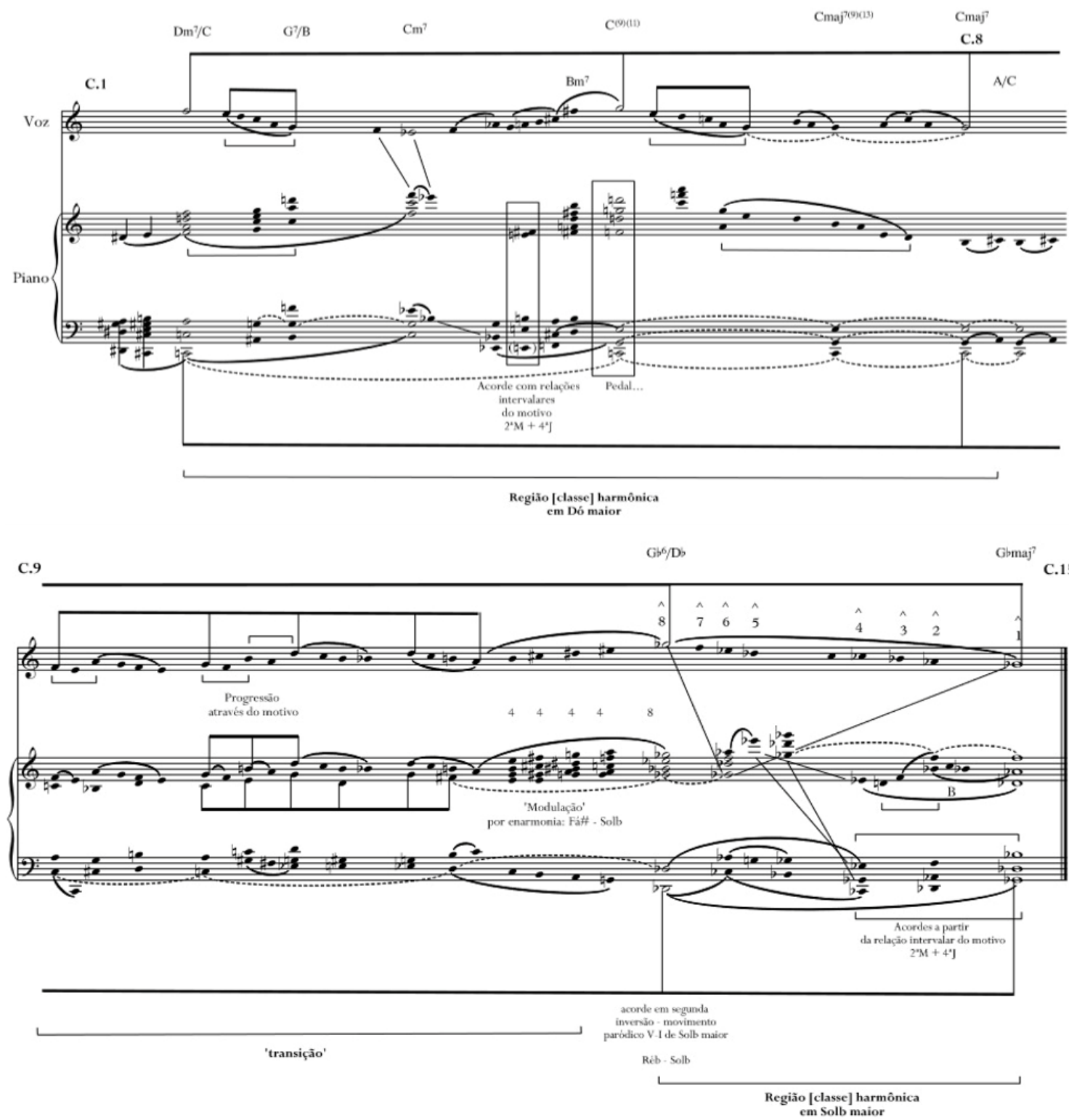

Fig. 12 - Abertura da proposta schenkeriana para repertórios não tonais.lves, Disclosure, análise do nível externo por Gabriel Duarte da Silva, USP.

Fonte: Gráfico gentilmente cedido por seu autor, Gabriel Duarte da Silva.

\section{4. $O$ ensino da percepção estendida ${ }^{46}$ através dos gráficos em mul- tiníveis}

Os aspectos da música aos quais Schenker se dedicou - performance, teoria, análise, estudo de manuscritos e preparação de edições - "eram inter-relacionados e, portanto,

46 Nossa proposta não é voltada a métodos da psicologia musical experimental, como descreve Temperley (2011), por exemplo. 
estabeleciam interlocuções em um formato integrado" (DRABKIN, 2006, p. 815). Os gráficos schenkerianos em multiníveis trazem em si um discurso sobre música através de uma notação musical que ao mesmo tempo requer a formação de uma imagem auditiva daquilo que se lê e desencadeia um acúmulo de performances interiores:

Um gráfico de Schenker é uma forma de escrita. Ele incorpora o discurso sobre uma peça de música. [...] Ao forçar seus praticantes a um mergulho no "interior" do organismo musical e aceitar os vestígios do ambiente em seus produtos finais (ou seja, os gráficos), a análise schenkeriana define uma relação de profunda ambivalência entre o objeto musical e a análise desse objeto. [...] Este cruzamento de fronteiras, ancorado como que por sua intenção comunicativa inequívoca, abre ricas possibilidades teóricas [...] $]^{47}$ (AGAWU, 1989, p. 285).

O movimento imagético importante na análise schenkeriana "não é aquele entre estratos sucessivos e superfície, mas entre o agregado de estratos (tomados como uma entidade única) e a superfície" (BLASIUS, 1996, p. 116). Cada etapa da distância entre a composição e sua estrutura encontra expressão nos gráficos em multiníveis, constituídos pelos níveis externo (foreground), intermediário (middleground) e fundamental (background) - e não apenas pelo nível fundamental que traz a Ursatz. O plano intermediário pode ser subdividido em várias camadas concebidas hierarquicamente. "No interior deste processo de audição estrutural, cada altura e cada progressão revelam seus significados como desdobramentos orgânicos ${ }^{48}$ da progressão básica" (SALZER, 1962 [1952], p. 207, grifo das autoras).

Os gráficos em multiníveis procuram considerar coletivamente as ações interativas das dimensões melodia, linha do baixo, estrutura harmônica e movimentos lineares (CADWALLADER; GAGNÉ, 2011 [1998], p. 106-107). O nível intermediário é o que traz as características motívicas e os movimentos harmônicos e contrapontísticos. Cada um desses níveis pode ser apresentado em um ou mais sistemas, a depender da obra que está sendo analisada, de maneira que o padrão de (a) até (c) frequentemente se estende até (e) ou (f).

Assim como ocorre com uma partitura anotada, uma análise gráfica "é um indicador confiável de intenções" (DUNSBY, 1999, p. 267). Se a opção do performer for a interação com um gráfico em multiníveis, as mudanças na textura, a escolha dos tipos de timbre para a performance, a opção por uma métrica elástica que acomode as inflexões rítmicas,

47 "A Schenker graph is a form of writing. It embodies discourse about a piece of music. [...] By forcing its practitioners to get 'inside' the musical organism, and to accept the traces of that environment on their final products (i.e. the graphs), Schenkerian analysis defines a profoundly ambivalent relation between musical object and the analysis of that object. [...] This crossing of boundaries, anchored as it were by its unequivocal communicative intent, opens up rich theoretical possibilities; it is, however, a potential source of confusion as well" (AGAWU, 1989, p. 285).

\footnotetext{
Observem que, por não estar em discussão nesse momento do nosso artigo, ocultamos a última frase da citação direta, que se refere às confusões em torno da análise schenkeriana. Agawu (1989, p. 281) encontrou a declaração que "confundiu gerações de alunos de Schenker": "Os exemplos musicais que acompanham este volume não são apenas ajudas práticas; eles têm o mesmo poder e convicção que o aspecto visual da própria composição impressa (o primeiro plano). Ou seja, a representação gráfica faz parte da própria composição, não sendo apenas um meio educacional" (SCHENKER, 1979, p. xxiii apud AGAWU, 1989, p. 281).

48 "Esse processo de derivar o subsequente do anterior foi frequentemente caracterizado por Schenker como 'orgânico' (organisch)". "This process of deriving the subsequent from the prior was frequently characterized by Schenker as 'organic' (organisch)" (BURKHART, 1978, p. 172).
} 
o movimento adiante do caráter formativo da repetição motívico-temática, o movimento dinâmico e a escuta expandida das tonicizações de áreas tonais secundárias articulam-se com os três ou mais níveis estruturais - ora condizendo e valorizando, ora obscurecendo e discordando destes. Sendo assim, o acesso atualizado aos gráficos em multiníveis perdem seu aparente caráter prescritivo original.

Schenker foi um pianista atuante e utilizava o piano para ensinar e elaborar suas análises. Um primeiro contato com a proposta schenkeriana pode se dar através de reduções rítmicas ao teclado (Fig. 13), formando uma redução figural - ou "contínuo imaginário" (CADWALLADER; GAGNÉ, 2011, p. 56-66), como gostamos de chamá-la:

Uma redução rítmica [redução por acordes] é uma estrutura metalinguística duracionalmente equivalente à obra ou passagem e que incorpora a linguagem do objeto analisado. Todos estamos familiarizados com as reduções rítmicas de tratados de contraponto, manuais de composição e livros teóricos. [...] Czerny a chama de "harmonia fundamental"; outros podem se referir a ela como um "resumo harmônico". [...] A redução rítmica parece, de fato, ocupar o espaço entre dois níveis estruturais, o plano intermediário e o plano externo, com excursões ocasionais para cima ou para baixo, dependendo da peça. Sua força pode muito bem residir nesta flexibilidade ${ }^{49}$ (AGAWU, 1989, p. 286-287).
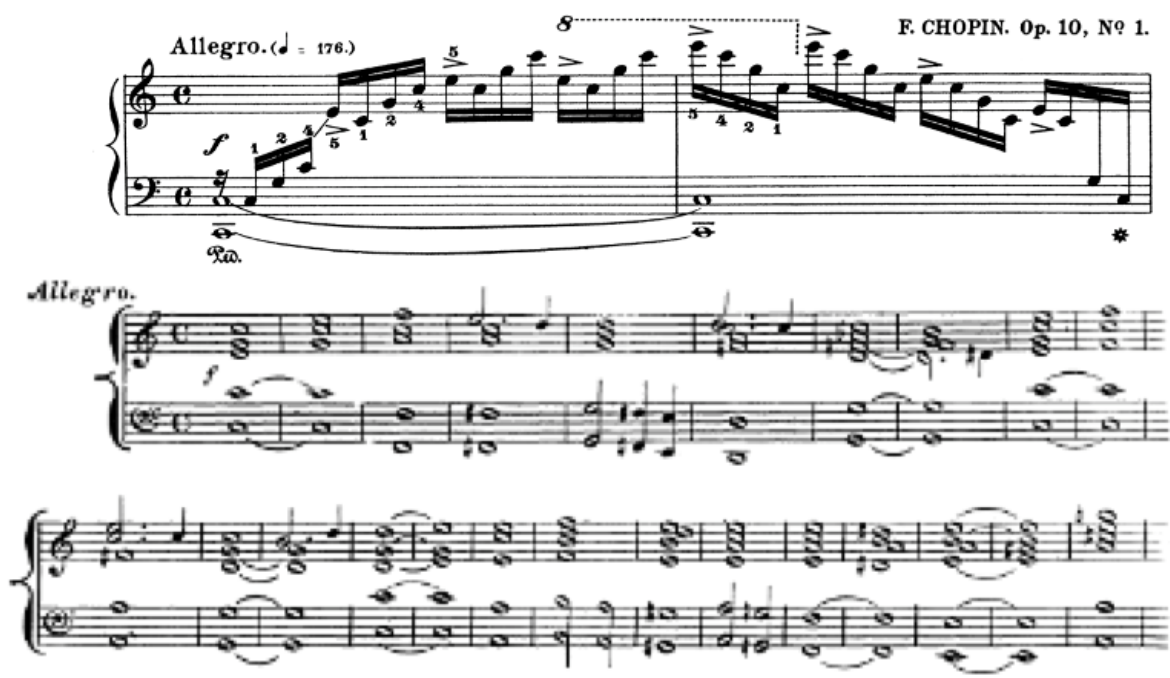

Fig. 13 - Contínuo imaginário na redução rítmicas apresentadas por Czerny (1848, p. 92-93 apud AGAWU, 1989, p. 287), sobre o Estudo op. 10, n. 1, de Chopin.

Fonte: Agawu (1989, p. 287).

49 "A rhythmic reduction is a metalinguistic structure which is durationally equivalent to the work or passage that embodies its object language. We are all familiar with rhythmic reductions from counterpoint treatises, composition manuals and theory text books. [...] Czerny calls it the 'ground-harmony'; others might refer to it as a 'harmonic summary'. [...] The rhythmic reduction would seem, in fact, to occupy the space between two nominally discrete levels of structure, the middleground and the foreground, with occasional excursions upwards or downwards depending on the piece. Its strength may well lie in this flexibility" (AGAWU, 1989, p. 286-287). 
Tudo o que acrescenta à notação musical a partir do momento da efetivação do contínuo imaginário é feito "de dentro e não de fora" (AGAWU, 1989, p. 285). "Schenker geralmente encerrava seus ensaios analíticos com observações sobre como a obra em questão deveria ser executada. [...] Para Schenker, o objetivo final do estudo [...] é alcançado apenas em sua aplicação à tarefa maior de dar vida à música"50 (BURKHART, 1978, p. 173):

\begin{abstract}
Dessa relação física - corporal e auditiva - com o instrumento e com a própria música emergiam seus insights teóricos. Suas análises, portanto, não tratam apenas da estrutura musical de um ponto de vista composicional, mas resgatam a dimensão instrumental da própria composição musical. Para Schenker, a criação musical está indissoluvelmente ligada à realização instrumental através do conceito de "improvisação". Os assuntos que Schenker aborda em A Arte da Performance auxiliam a compreender essa dupla dimensão de seu pensamento, compositiva e interpretativa, assim como sua concepção de uma arte em constante fluxo, que se renova a cada interpretação (BARROS; GERLING, 2007, p. 142).
\end{abstract}

A ênfase de Schenker na manutenção da escuta junto à tonalidade principal [tonality] ao longo de toda a obra faz com que as tonalidades de passagem [keys] produzam uma expansão perceptiva auditiva. Uma expansão da escuta ocorre se, após a apreensão auditiva da tonalidade principal, cada nova alteração em determinada passagem ou seção de uma composição for entendida tanto em sua tradicional função local como na qualidade de expansão da tonalidade inicial. Essa experiência sensibiliza o ouvinte para a percepção da tonalidade como uma entidade elástica e resiliente, que se molda ao contexto composicional.

A análise concebida por Schenker (Fig. 14) ${ }^{51}$ ilustra a possibilidade de escuta da tonalidade do Estudo op. 10, n. 8, em Fá maior, de Chopin seja expandidada pela ocorrência da seção em Ré menor - evidenciada pela indicação III\# (comp. 40) associada à dominante de Ré menor. Sendo assim, ao se buscar a percepção da obra como um todo, a expansão provocada pela cromatização da passagem entre os compassos 40 e 55 passa a ser mais identitária do que uma interpretação com enfoque em uma modulação para Ré menor. Sendo assim, esta análise constitui um bom exemplo de percepção do conceito de monotonalidade.

\footnotetext{
50 "Schenker usually ended his analytic essays with remarks on how the work in question should be played. [...] For him, the ultimate goal of the study [...] is reached only in its application to the greater task of bringing the music to life" (BURKHART, 1978, p. 173).

51 O nível externo deve ser consultado no original. Não foi incluído aqui por sua extensão.
} 


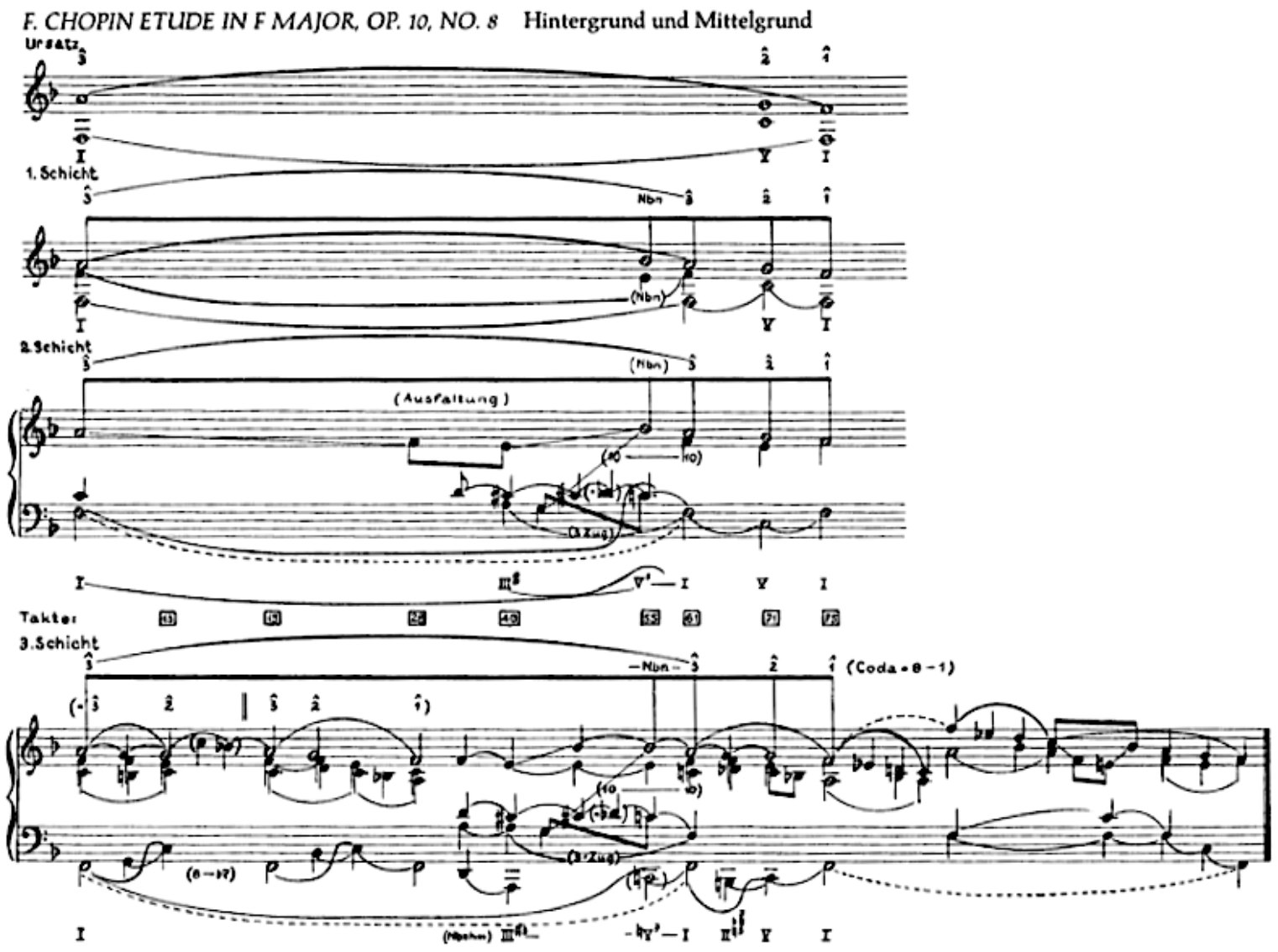

Fig. 14 - Análise de Heinrich Schenker, sobre o Estudo op. 10, n. 8, de Chopin.

Fonte: Schenker (2012 [1969], p. 47).

Os gráficos em multiníveis guardam um parentesco com a composição, o ensino da composição (AGAWU, 1989, p. 290) e a prática da recomposição:

[...] o que o mestre compositor pretendeu realizar em som (e conseguiu) é o que o não compositor interpreta a partir dos sons. Schenker expressa essa relação complementar referindo-se ao compositor como criativo (nachschaffend) e ao não-compositor como re-criativo (nachschqffend). [...] Um objetivo da atividade de Schenker foi ajudar compositores e não compositores a desenvolver essa faculdade interpretativa ${ }^{52}$ (SNARRENBERG, 1997, p. 142).

A proximidade entre recomposição e análise emerge da interpretação. A metalinguagem gráfica possibilita que se fale de música através de um sistema simbólico musical, dispensando uma recorrência à linguagem verbal ou escrita. E esta apreciação qualitativa aparentemente silenciosa torna disponível uma imagem mental de performances interiores dinâmicas entre si.

52 "[...] what the master composer intended to realize in tone (and succeeded) is what the noncomposer interprets from the tones. Schenker expresses this complementary relationship by referring to the composer as creative (schaffend) and the noncomposer as re-creative (nachschqffend). [...] The goal of Schenker's activity was to help composers and noncomposers alike develop that interpretive faculty" (SNARRENBERG, 1997, p. 142). 


\section{Considerações finais}

Pelo bem e pelo mal, apenas a leitura de textos de análise não é suficiente para que um músico compreenda a que exatamente se refere uma proposta analítica. Uma prévia e intensa experiência musical, somada à prática analítica deliberada, são imprescindíveis à compreensão do contexto analítico musical.

Um aprofundado envolvimento com a proposta schenkeriana permite a percepção do significado criativo, vívido e particular de cada obra musical, subjacente aos planos estruturais dos gráficos em multiníveis, por mais áridos que possam parecer para alguns a uma primeira vista.

Embora Schenker tivesse mantido o forte vínculo com um repertório marcadamente tonal e tivesse resgatado práticas analíticas pregressas, sua forma de abordagem refletiu - até mesmo por essas razões - o ideário modernista:

Ele [Schenker] gostaria de voltar no tempo, mas com sua teoria reinventou os clássicos sob o signo do modernismo. Ele era um antimodernista entusiasta, é claro, mas por trás disso - e talvez apesar dele mesmo - acabou sendo um modernista relutante ${ }^{53}$ (COOK, 2007, p. 139).

O distanciamento no tempo, aliado á incorporação de vivências diferenciadas, nos permite hoje dialogar com percepções que abriram perspectivas analíticas e conseguiram superar as polêmicas discussões surgidas desde o aparecimento da teoria de Schenker nas primeiras décadas do século XX. Assim é possível afirmar que a experiência teórico-analítica neo-schenkeriana incorpora variados repertórios, desenvolve uma direção didática coerente, através de tópicos, como: uma forma diferente do estudo do contraponto, através dos movimentos das vozes condutoras; a diferença entre a percepção do acorde como gramática e como significado harmônico; a comparação do contraste entre os motivos schenkeriano e schoenberguiano; a percepção estendida, possibilitando sempre a incorporação do todo da peça que é analisada.

Um projeto que mudou tanto a análise musical se apresenta aberto a novos aspectos do original, contribuições históricas, que uma teoria revolucionária recebe e passa a viver. O que não muda, porém, é a análise ser sempre uma interpretação, um ato artístico, independente de como será ou não aplicada. 


\section{Referências bibliográficas}

AGAWU, Kofi. Notation in Theory and Practice. Music Analysis, v. 8, n. 3, p. 275-301, 1989.

ALMADA, Carlos; BARROS, Guilherme; GERLING, Cristina Caparelli; NOGUEIRA, Ilza; SOUZA, Rodolfo Coelho de. The Reception and the Dissemination of European Theories in Brazil: Riemann, Schenker and Schoenberg. Zeitschrift der Gesellschaft für MusikTheorie, v. 15, n. 2, p. 129-154, 2018.

BAKER, James. Schenkerian Analysis and Post-Tonal Music. In: BEACH, David (Ed.). Aspects of Schenkerian Theory. New Heaven and London: Yale University Press, 1983. p. 153-186.

BEACH, David. Schenkerian Theory. Music Theory Spectrum, v. 11, n. 1, p. 3-14, 1989.

(Ed.). Aspects of Schenkerian Theory. New Heaven and London: Yale University Press, 1983.

BLASIUS, Leslie. Schenker's Argument and the Claims of Music Theory. Cambridge Studies in Music Theory and Analysis. Cambridge: Cambridge University Press, 1996.

BOSS, Jack. Schoenberg's Op. 22 Radio Talk and Developing Variation in Atonal Music. Music Theory Spectrum, v. 14, n. 2, p. 125-49, 1992.

BURKHART, Charles. Schenker's Motivic Parallelisms. Journal of Music Theory, v. 22, n. 2, p. $145-175,1978$.

CADWALLADER, Allen; GAGNÉ, David. Analysis of Tonal Music: A Schenkerian Approach. 3. ed. Oxford: Oxford U. Press, 2011 [1998].

Student Workbook to Accompany Analysis of Tonal Music: A Schenkerian Approach. 3. ed. Oxford: Oxford University Press, 2012 [2007].

COOK. Nicholas. The Schenker Project: Culture, Race, and Music Theory in Fin-de-siècle Vienna. Oxford: Oxford University Press, 2007.

A Guide to Musical Analysis. NY: George Braziller, 1987.

CORREIA Renata Coutinho de Barros. Análise e Performance Musical: perspectivas de pesquisa, influências mútuas e abordagem crítica. Tese (Doutorado) - Programa de PósGraduação em Música, Escola de Comunicações e Rates, Universidade de São Paulo, 2021. 
DODSON, Alan. JONAS, Oswald. Heinrich Schenker and Great Performers. Theory and Practice, Music Theory Society, v. 28, p. 123-135, 2003.

DRABKIN, William. Heinrich Schenker. In: CHRISTENSEN, Thomas (Ed.). The Cambridge History of Western Music Theory. Cambridge: Cambridge University Press, 2006. p. 812843.

DUNSBY, Jonathan. Recent Schenker: The Poetic Power of Intelligent Calculation (Or, The Emperor's Second Set of New Clothes). Music Analysis, v. 18, n. 2, p. 263-273, 1999.

FORTE, Allen. Concepts of Linearity in Schoenberg's Atonal Music: A Study of the Opus 15 Song Cycle. Journal of Music Theory, v. 36, n. 2, p. 285-382, 1992.

New Approaches to the Linear Analysis of Music. Journal of the American Musicological Society, v. 41, n. 2, p. 315-348, 1988.

Heinrich Schenker as an Interpreter of Beethoven's Piano Sonatas. 19th-Century Music, v. 8, n. 1, p. 3-28, 1984.

FORTE, Allen; GILBERT; Steven. Introduction to Schenkerian Analysis. NY: W. W. Norton, 1982.

FRAGA, Orlando. Progressão linear: uma breve introdução à teoria de Schenker. Londrina: Eduel, 2011.

GERLING, Cristina Capparelli; BARROS, Guilherme. Glossário de termos schenkerianos. Salvador: Tema, 2020.

HUFF, David. Prolongation in Post-Tonal Music: A Survey of Analytical Techniques and Theoretical Concepts with an Analysis of Alban Berg's Op. 2, No. 4, Warm Die Lüfte. Thesis (Master of Music, Music Theory). Univ. North Texas, 2010.

KOSLOVSKY, John.Tracing the Improvisatory Impulse in Early Schenker Theory. Intégral, v. 24, p. 57-79, 2010.

MEEÙS, Nicholas. Heinrich Schenker: Une introduction. Liège, Mardaga, 1993. Traduzido por Luciane Beduschi, sob o título Análise schenkeriana. Disponível em: http://nicolas.meeus.free.fr/Cours/trad/Introducao.pdf. Acesso em: 24 abr. 2021.

MOREIRA, Adriana Lopes da Cunha. A poética nos 16 Poesilúdios para piano de Almeida Prado: análise musical. Dissertação (Mestrado). 2 v. 411 p. Campinas: Universidade Estadual de Campinas, Instituto de Artes, 2002. 
NEUMEYER, David; TEPPING, Susan. A Guide to Schenkerian Analysis. Englewood Cliffs, NJ: Prentice Hall, 1992.

PELES, Stephen; DEMBSKI, Stephen; MEAD, Andrew; STRAUS, Joseph N. (Ed.). The Collected Essays of Milton Babbitt. Princeton: Princeton University Press, 2012.

RIFKIN, Deborah. A Theory of Motives for Prokofiev's Music. Music Theory Spectrum, v. 26, n. 2, p. 265-290, 2004.

RINK, John. Schenker and Improvisation. Journal of Music Theory, v. 37, n. 1, p. 1-54, 1993.

ROTHSTEIN, William. The Americanization of Heinrich Schenker. In Theory Only, v. 9, n. 1, p. 5-17, 1986.

SALZER, Felix. Structural Hearing. New York: Dover, 1962 [1952].

BARROS, Guilherme. A Humoresque op. 20 de Schumann e a Urlinie de Schenker. Revista Música, PPGMUS-ECA-USP, v. 18, n. 1, p. 1-17, 2018.

BARROS, Guilherme; GERLING, Cristina Capparelli. Análise schenkeriana: interpretação e crítica. In: BUDASZ, Rogério (Org.). Pesquisa em música no Brasil: métodos, domínios, perspectivas. Goiânia: ANPPOM, 2009. p. 87-121.

2007.

Análise schenkeriana e performance. Opus, Goiânia, v. 13, n. 2, p. 141-160, dez.

SCHENKER, Heinrich. Der Tonwille: Pamphlets/Quartely Publication in Witness of the Immutable Laws of Music, Offered to a New Generation of Youth. v.1. NY: Oxford University Press, 2004 [1921-1923].

. Five graphic music analysis. NY: Dover, 1969.

SCHMALFELDT, Janet. In the Process of Becoming: Analytic and Philosophical Perspectives on Form in Early Nineteenth-Century Music. Oxford Studies in Music Theory. Oxford: Oxford University Press, 2011.

SCHOENBERG, Arnold. Fundamentos da composição musical. 3ed. SP: Edusp, 2015 [1967].

SNARRENBERG, Robert. Schenker's Interpretative Practice. Cambridge: Cambridge University Press, 1997. 
STRAUS, Joseph. Composing out in atonal music. Orpheus Institute, Ghent, Belgium: International Easter Academy of Music Theory, April, 2003.

. The Problem of Prolongation in Post-Tonal Music. Journal of Music Theory, v. $31 \mathrm{n}$.

1, p. 1-21, 1987.

STRAUS, Joseph. Introduction to post tonal theory. 4. ed. NY: W. W. Norton, 2016.

TEMPERLEY, David. Composition, Perception, and schenkerian Theory. Music Theory Spectrum, v. 33, n. 2, p. 146-168, 2011. 